\title{
ForCent model development and testing using the Enriched Background Isotope Study experiment
}

\author{
William J. Parton, ${ }^{1}$ Paul J. Hanson, ${ }^{2}$ Chris Swanston, ${ }^{3}$ Margaret Torn, ${ }^{4}$ \\ Susan E. Trumbore, ${ }^{5}$ William Riley, ${ }^{4}$ and Robin Kelly ${ }^{1}$ \\ Received 30 October 2009; revised 7 May 2010; accepted 9 June 2010; published 5 October 2010.
}

[1] The ForCent forest ecosystem model was developed by making major revisions to the DayCent model including: (1) adding a humus organic pool, (2) incorporating a detailed root growth model, and (3) including plant phenological growth patterns. Observed plant production and soil respiration data from 1993 to 2000 were used to demonstrate that the ForCent model could accurately simulate ecosystem carbon dynamics for the Oak Ridge National Laboratory deciduous forest. A comparison of ForCent versus observed soil pool ${ }^{14} \mathrm{C}$ signature $\left({ }^{14} \mathrm{C}\right)$ data from the Enriched Background Isotope Study ${ }^{14} \mathrm{C}$ experiment (1999-2006) shows that the model correctly simulates the temporal dynamics of the ${ }^{14} \mathrm{C}$ label as it moved from the surface litter and roots into the mineral soil organic matter pools. ForCent model validation was performed by comparing the observed Enriched Background Isotope Study experimental data with simulated live and dead root biomass $\Delta{ }^{14} \mathrm{C}$ data, and with soil respiration $\Delta{ }^{14} \mathrm{C}$ (mineral soil, humus layer, leaf litter layer, and total soil respiration) data. Results show that the model correctly simulates the impact of the Enriched Background Isotope Study ${ }^{14} \mathrm{C}$ experimental treatments on soil respiration $\Delta{ }^{14} \mathrm{C}$ values for the different soil organic matter pools. Model results suggest that a two-pool root growth model correctly represents root carbon dynamics and inputs to the soil. The model fitting process and sensitivity analysis exposed uncertainty in our estimates of the fraction of mineral soil in the slow and passive pools, dissolved organic carbon flux out of the litter layer into the mineral soil, and mixing of the humus layer into the mineral soil layer.

Citation: Parton, W. J., P. J. Hanson, C. Swanston, M. Torn, S. E. Trumbore, W. Riley, and R. Kelly (2010), ForCent model development and testing using the Enriched Background Isotope Study experiment, J. Geophys. Res., 115, G04001, doi:10.1029/2009JG001193.

\section{Introduction}

[2] Decomposition of root and leaf litter is a critical process for releasing soil nutrients for plant growth and for providing substrate for the formation of soil organic matter. This process is included in all of the major ecosystem models (see Century [Parton et al., 1987], Biome-BGC [Running and Coughlan, 1988], DNDC [Li et al., 1994], Roth-C [Coleman and Jenkinson, 1996]). Root and leaf litter substrate is incorporated into soil organic matter pools with rapid, intermediate, and slow turnover times. The conceptual development of these pools was based on studies

\footnotetext{
${ }^{1}$ Natural Resource Ecology Laboratory, Colorado State University, Fort Collins, Colorado, USA.

${ }^{2}$ Oak Ridge National Laboratory, Oak Ridge, Tennessee, USA. USA.

${ }^{3}$ Northern Research Station, U.S. Forest Service, Houghton, Michigan,

${ }^{4}$ Lawrence Berkeley National Laboratory, Berkeley, California, USA.

${ }^{5}$ School of Physical Sciences, University of California, Irvine, California, USA.

Copyright 2010 by the American Geophysical Union. 0148-0227/10/2009JG001193
}

of the impact of root and leaf litter decay on soil organic matter levels and nutrient dynamics [Meentemeyer, 1978; Melillo et al., 1982; Hobbie, 1996; Parton et al., 2007a].

[3] The most common technique for studying these decomposition dynamics is to use litter bags (reviewed by Wieder and Lang [1982] and Parton et al. [2007a]). Most litter bag studies have been run for relatively short time periods (three years or less [Shanks and Olson, 1961; Lousier and Parkinson, 1976; McClaugherty et al., 1985; Aerts et al., 2003]); however, a few studies were run for a longer period time (five or more years [Trofymow et al., 2002; Parton et al., 2007a]). Results from the long-term studies suggest that $5-20 \%$ of the initial litter plant biomass is stabilized into the slow turnover soil organic matter pool. The recent global litter decay study by Parton et al. [2007a] showed photodegradation can greatly enhance surface litter decay rates for dry grassland ecosystems; however, photodegradation does not seem to be an important process for humid grasslands and forest ecosystems. The major limitation of litter bag techniques, however, is that they do not directly evaluate the subsequent fate of nutrients and organic matter released from litter bags [see Dornbush et al., 2002]. 
[4] A number of studies using isotopic tracers $\left({ }^{13} \mathrm{C}\right.$ and ${ }^{14} \mathrm{C}$ ) have been conducted to address gaps in the scientific knowledge of the relationships between litter decomposition and the formation of soil organic matter [Jenkinson, 1971; Wang et al., 1996]. Since the isotopic signature of soil organic matter is similar to the vegetation system under which it was formed, a difference in plant versus soil $\Delta{ }^{13} \mathrm{C}$ suggests a relatively recent change in plant cover. Isotopic approaches have been used to track changes in ecotone boundaries [Steuter et al., 1990; McClaran and McPherson, 1995], detect land use conversion from tropical $\mathrm{C}_{3}$-dominated forests to $\mathrm{C}_{4}$-dominated cropping systems [Osher et al., 2003]. Estimates of the minimum age of a soil organic matter pool or the mean residence time of the organic material are possible using ${ }^{14} \mathrm{C}$ dating [Paul et al., 1997], and may be used to track changes in slow and passive soil organic matter. Both ${ }^{13} \mathrm{C}$ and ${ }^{14} \mathrm{C}$ signatures $\left({ }^{13} \mathrm{C}\right.$ and $\Delta{ }^{14} \mathrm{C}$, respectively) are used to track litter decomposition and soil organic matter formation and stabilization [Follett et al., 2007]. The results from these studies support the three-pool soil organic matter structure common in ecosystem soil $\mathrm{C}$ cycle models.

[5] This paper describes the use of the Enriched Background Isotope Study $\Delta{ }^{14} \mathrm{C}$ [Hanson et al., 2005] litter and root experiments to calibrate, develop, and test a mechanistically improved forest version of the DayCent model (ForCent). The main objective of this paper is to determine how well the extensive Enriched Background Isotope Study $\Delta{ }^{14} \mathrm{C}$ data sets can be used to determine the turnover rates of the different soil organic matter pools using a processbased ecosystem model. We utilized the classic modeling approach by using part of the observed data to develop the new model and then selected a segment of the observed data to perform a true model validation. A detailed description of the new ForCent model, the procedure used to calibrate the model, limitations of the ForCent model, and a comparison of the model results with the observed data sets are also presented. In addition, we included a sensitivity analysis of the model to the assumed atmospheric $\Delta{ }^{14} \mathrm{C}$ values and the fraction of mineral soil carbon in slow and passive fractions.

[6] The ForCent model described here is better poised to address outstanding issues in the terrestrial carbon cycle, including: (1) the partitioning of soil carbon turnover between autotrophic and heterotrophic sources, (2) the partitioning of heterotrophic respiration sources between aboveground litter decomposition and belowground root detritus decomposition, and (3) the clarification of pathways leading from leaf and root detritus to long-term stabilization of soil organic matter. By incorporating a new understanding of important forest carbon cycling pools and processes, ForCent is better prepared to address questions such as the influence of climatic change on the longevity of new carbon additions to soils and the fate of long-lived storage pools through time.

\section{Methods}

\subsection{Enriched Background Isotope Study}

[7] The Enriched Background Isotope Study project [Trumbore et al., 2002; Hanson et al., 2005; Swanston et al., 2005] started in the fall of 2000 on the U.S. Department of Energy's National Environmental Research Park near
Oak Ridge, Tennessee. The Enriched Background Isotope Study plots are located on ridgetop and upslope positions which are dominated by oak forests that range in age from 65 to 150 years. Available aerial photographs show that the Enriched Background Isotope Study sites are located on the east branch of the watershed which had a closed canopy forest cover in 1935. The exact date for a prior clear-cut disturbance for the Enriched Background Isotope Study plots is not exactly known; however, the state of the forest in 1935 suggests that forest regrowth started after a 1900 clear-cut. The experimental sites included two soil types and two levels of ${ }^{14} \mathrm{C}$ exposure in 1999. Reciprocal transplants of enriched versus near-background litter were established on sites that had large (western site) and minimal (east site) exposure to enhanced atmospheric levels of ${ }^{14} \mathrm{C}$ in 1999. Enriched ${ }^{14} \mathrm{C}$ leaf litter was collected from the western site during the fall of 2000 , while background ${ }^{14} \mathrm{C}$ litter was collected from the eastern site during the same time period. Near background and enriched ${ }^{14} \mathrm{C}$ leaf litter were added to the plots in May 2001, with continued additions of elevated and ambient leaf litter (during winter months) for the next two years. Plots in the replicated experimental design included those with: (1) ${ }^{14} \mathrm{C}$ enriched soil carbon, root litter, and leaf litter; (2) ${ }^{14} \mathrm{C}$ enriched roots, soil carbon, and near background leaf litter; (3) near-background roots, soil carbon, and elevated ${ }^{14} \mathrm{C}$ leaf litter; and (4) near background leaf litter, roots, and soil carbon. The ${ }^{14} \mathrm{C}$ content of surface litter, humus, mineral soil layers, and soil respiration rates were measured from 2001 to 2005. As of 2004, natural background ${ }^{14} \mathrm{C}$ leaf litter was allowed to fall into the treatment plots.

[8] Atmospheric ${ }^{14} \mathrm{C}$ levels elevated during the aboveground testing of nuclear weapons have been used as a tracer for the interpretation of biological carbon pathways for many years; however, that tracer is now returning to prebomb levels limiting the sensitivity of such observations [Swanston et al., 2005]. The local and unexpected enrichment of background ${ }^{14} \mathrm{C}$ on the Oak Ridge Reservation provided a unique opportunity to address soil carbon cycling at annual and even subannual timescales allowing for the direct testing of soil carbon cycle mechanisms in forests at previously unresolved time intervals [Trumbore et al., 2002; Fröberg et al., 2007].

\subsection{DayCent Model Description}

[9] The DayCent model [Kelly et al., 2000; DelGrosso et al., 2001a, 2001b; Parton et al., 2001] is the daily version of the Century model [Parton et al., 1987] developed to simulate daily trace gas fluxes $\left(\mathrm{CO}_{2}, \mathrm{~N}_{2} \mathrm{O}, \mathrm{NO}_{\mathrm{x}}\right.$, $\mathrm{CH}_{4}, \mathrm{~N}_{2}$ ) from ecosystems. The objective was to develop a model capable of simulating full greenhouse gas fluxes and net ecosystem exchange of carbon for agricultural systems, grasslands, savanna, and forest systems. The model has been used extensively to simulate the ecosystem dynamics of grasslands and forest and cropping systems in the U.S. [Kelly et al., 2000; DelGrosso et al., 2001a, 2005]. DelGrosso et al. [2005] recently used the DayCent model to simulate the impact of agricultural management practices on soil carbon levels, trace gas fluxes, and crop yields for agricultural systems in the U.S. at site, regional, and national levels. The DayCent model has also been used to simulate the impact of nitrogen deposition, changing $\mathrm{CO}_{2}$ levels, and 


\section{DAYCENT MODEL}

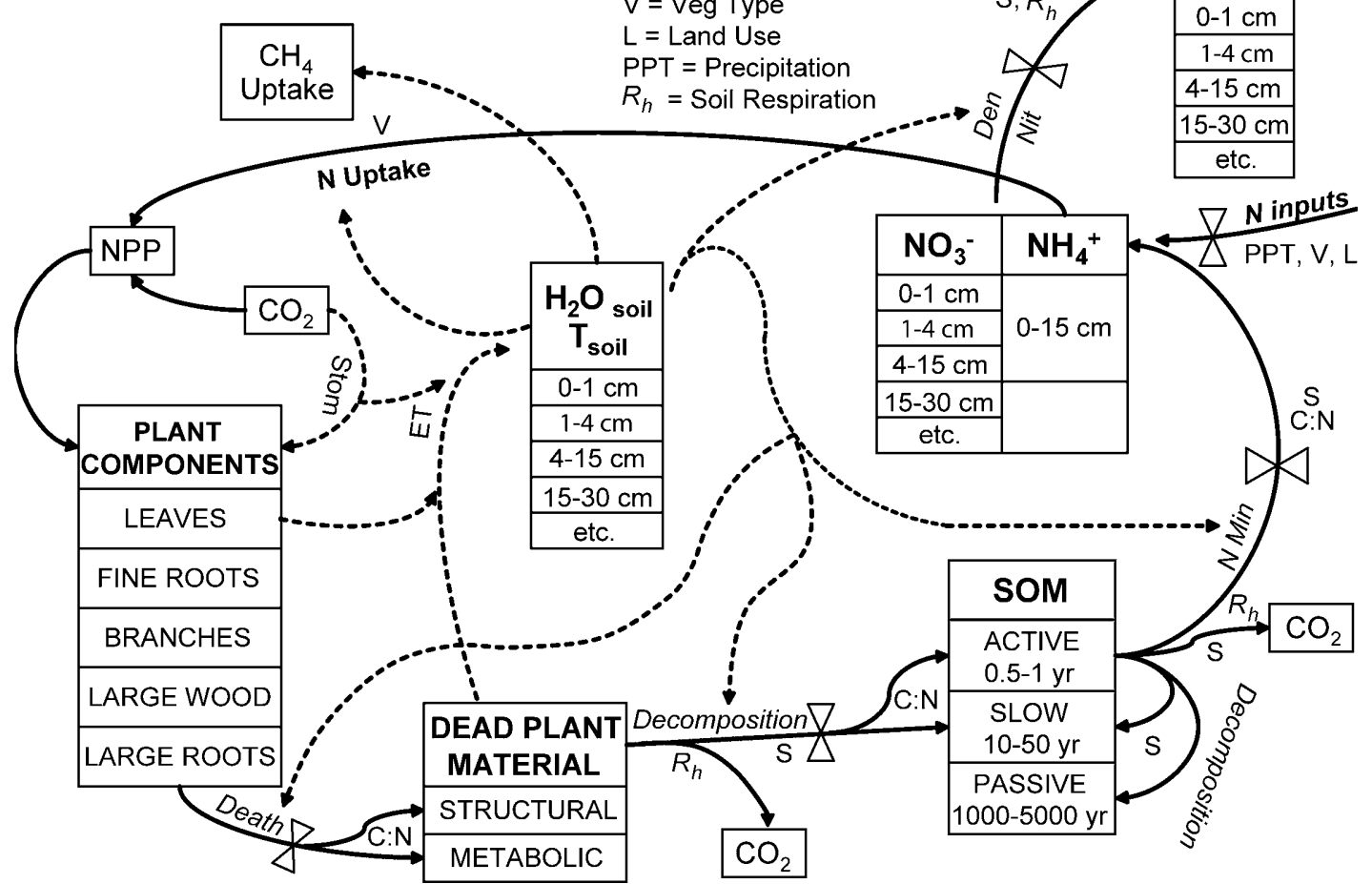

Figure 1. Flow diagram and components of the ForCent forest growth model. The ForCent model simulates $\Delta 14 \mathrm{C}$ and $\Delta 13 \mathrm{C}$ content for all of the carbon state variables and flows in the model (e.g., soil respiration).

future climatic changes [Pepper et al., 2005; Parton et al., 2007b; Luo et al., 2008] on grassland and forest systems. The model simulates soil nutrients $(\mathrm{N}$ and $\mathrm{P})$ and carbon dynamics, trace gas fluxes $\left(\mathrm{N}_{2} \mathrm{O}, \mathrm{NO}_{\mathrm{x}}, \mathrm{N}_{2}\right.$, and $\left.\mathrm{CH}_{4}\right)$, plant production and nutrient uptake, and soil water and temperature dynamics (Figure 1). The DayCent model uses a daily time step to simulate trace gas fluxes and soil nutrient and carbon dynamics, one half hour time step for the soil water flow, and daily time step for the plant production submodel.

[10] The plant production submodel simulates the growth of forests, grasslands, and savanna systems. Important processes represented in the plant growth submodel include plant death, plant phenology, uptake of soil nutrients, and growth of different plant parts. The factors controlling plant growth are daily solar radiation, soil water and temperature, live leaf area, and soil nutrient uptake by plants. A detailed description of the plant growth submodel is presented by Kelly et al. [2000] and DelGrosso et al. [2001a]. The plant growth model simulates dynamic allocation of carbon to the different plant parts as a function of water and nutrient stress. This paper presents a detailed description of the most recent changes to the forest plant growth submodel.

[11] The soil temperature and water submodels simulate daily soil temperature and water content for the soil layers represented in the model. The soil temperature model is described by Eitzinger et al. [2000], while Parton et al. [1998] present a detailed description of the soil water model. The soil water model simulates saturated and unsaturated water flow, surface runoff, and deep drainage below the plant rooting zone. Darcy water flow equations are used to simulate water flow between soil layers using a one-half hour time step. Anaerobic conditions resulting from snowmelt into frozen soil layers are represented in the model. Soil temperatures are simulated for each $5 \mathrm{~cm}$ depth increment using an analytical solution to the soil heat flow equations. The soil temperature and water models have been tested extensively [Frolking et al., 1998; Eitzinger et al., 2000; DelGrosso et al., 2001a].

\subsection{ForCent Model Changes}

[12] The major changes to the ForCent model include: (1) adding a surface litter slow organic matter pool (humus layer); (2) altering the surface litter decay submodel; (3) adding the Parton et al. [1978] root growth model; (4) adding a plant stored carbohydrate pool; and (5) including the impact of phenology on seasonal plant growth patterns. The ForCent model divided the slow pool into a surface slow pool (humus) and a mineral soil slow pool (see Figure 2). The need for this change was emphasized by Kelly et al. [1997]. As part of this change, we added a flow that simulates the physical mixing of the humus layer into the soil mineral slow pool. The surface litter layer corresponds to the sum of the Century surface litter pools (structural and metabolic pools) and the surface microbial biomass pool.

[13] The Riley et al. [2009] (Radix 1.0) and Parton et al. [1978] root growth models assume that live fine roots are composed of roots with fast and slow turnover rates. The roots with fast turnover rates are called juvenile roots, and roots with slow turnover rates are called mature roots. Riley 


\section{EBIS ForCent C Pools}

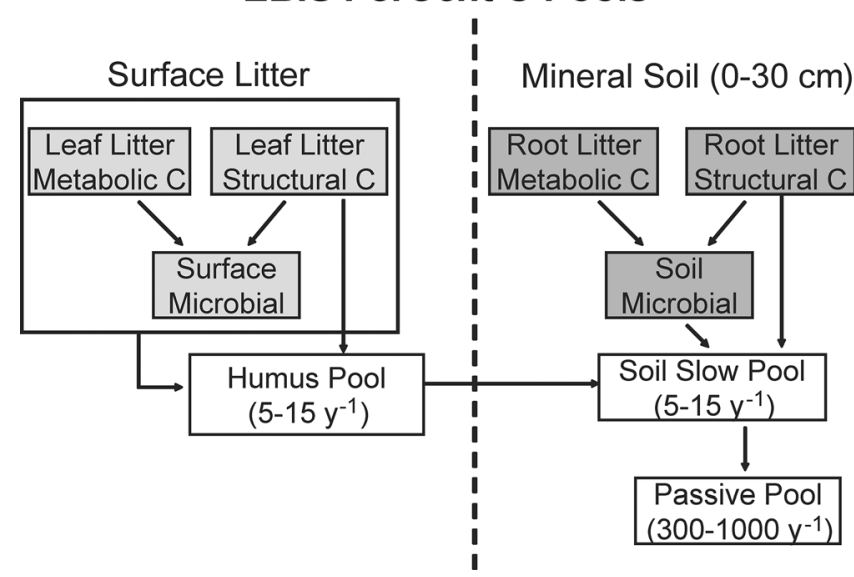

Figure 2. Revised flow diagram for the surface organic and mineral soil layers in the ForCent model.

et al. [2009] suggest that juvenile roots have turnover times $<1.0$ year, while mature roots have turnover times $>10.0$ years. The ForCent model has incorporated a revised version of the Parton et al. [1978] root growth model (Figure 3). The main structural change for the ForCent root model was to combine the juvenile and nonsuberized roots into juvenile roots, and then refer to the suberized roots as mature roots. The major process included in the Parton et al. [1978] model includes maintenance respiration, growth of new roots, aging of juvenile roots, and root death. Root maintenance respiration and root death are calculated as a function of soil water content of the wettest layer and soil temperature, while aging of roots is a function of soil temperature. The impacts of soil water and temperature on these processes are represented using the Parton et al. [1978] model, while the maximum rates for root aging and root death were parameterized based on the live root biomass data from the Enriched Background Isotope Study [Joslin et al., 2006].

[14] The revised model uses the original Century equations [Parton et al., 1987] to control litter decay for the soil pools (structural and metabolic dead roots, soil microbial biomass, and slow and passive soil organic matter) within the mineral soil layer. Surface litter decay rates are now a function of time since rainfall, average soil surface temperature, and soil water content of the $0-4 \mathrm{~cm}$ soil layer using equation (1):

$$
\mathrm{Di}=\mathrm{Ki}^{*} \mathrm{Bi}^{*}{ }^{*}{ }^{*} \mathrm{~F}(\mathrm{Ts}){ }^{*} \mathrm{~F}(\mathrm{w})
$$

where $\mathrm{Di}$ is the decomposition rate $\left(\mathrm{g} \mathrm{C} \mathrm{m}^{-2} \mathrm{~d}^{-1}\right)$ of ith soil pool $(I=1,2,3$, and 4 for the surface metabolic, structural, microbial and humus pools), $\mathrm{Ki}$ is the maximum decay rate $\left(\mathrm{d}^{-1}\right)$ for the ith surface litter pool, $\mathrm{Bi}$ is the carbon level $\left(\mathrm{g} \mathrm{C} \mathrm{m}^{-2}\right)$ in the ith surface litter pool, $\mathrm{R}$ is the rainfall event multiplier (set equal to 1.0 for no precipitation days and 3.0 for days when precipitation is $>10.0 \mathrm{~mm}$ ), $\mathrm{F}$ (Ts) is the impact of temperature on decomposition (Figure 4a), and $\mathrm{F}(\mathrm{w})$ is the effect of soil water on litter decay (Figure 4b). The same temperature and water functions are used to simulate decay rates for the soil mineral pools $(\mathrm{R}$ is not used for the mineral soil pools). Continuous soil respiration data from the Oak Ridge National Laboratory [Hanson et al., 2005] show that soil respiration rates from the surface litter increase rapidly following rainfall events and then decrease as the soil litter dries out (generally within 24 to $36 \mathrm{~h}$ ).

[15] The ForCent model includes a stored carbohydrate pool and currently assumes that gross photosynthesis is equal to two times the net plant growth rates [Waring et al., 1998; DeLucia et al., 2007; Litton et al., 2007]. It predicts potential net plant growth rates as a function of air temperature, water stress, and light interception, and then reduces these rates if nutrients are not available. Stored carbohydrate is used to support growth of new leaves in the spring, with $50 \%$ of new leaf growth coming from this pool. Carbon in the stored carbohydrate pool is the source for growth and maintenance respiration. The model assumes that growth respiration is equal to $23.3 \%$ of the total growth of the different plant parts [Hanson et al., 2003a], while maintenance respiration rates are calculated using a model developed by Ryan et al. [1995] for live leaves, branches, coarse roots, and stems. The Ryan respiration model assumes that each plant part has a specific respiration rate and uses an exponential function to represent the effect of temperature on maintenance respiration $\left(\mathrm{Q}_{10}=2.0\right)$. The ForCent model assumes that maintenance respiration rates

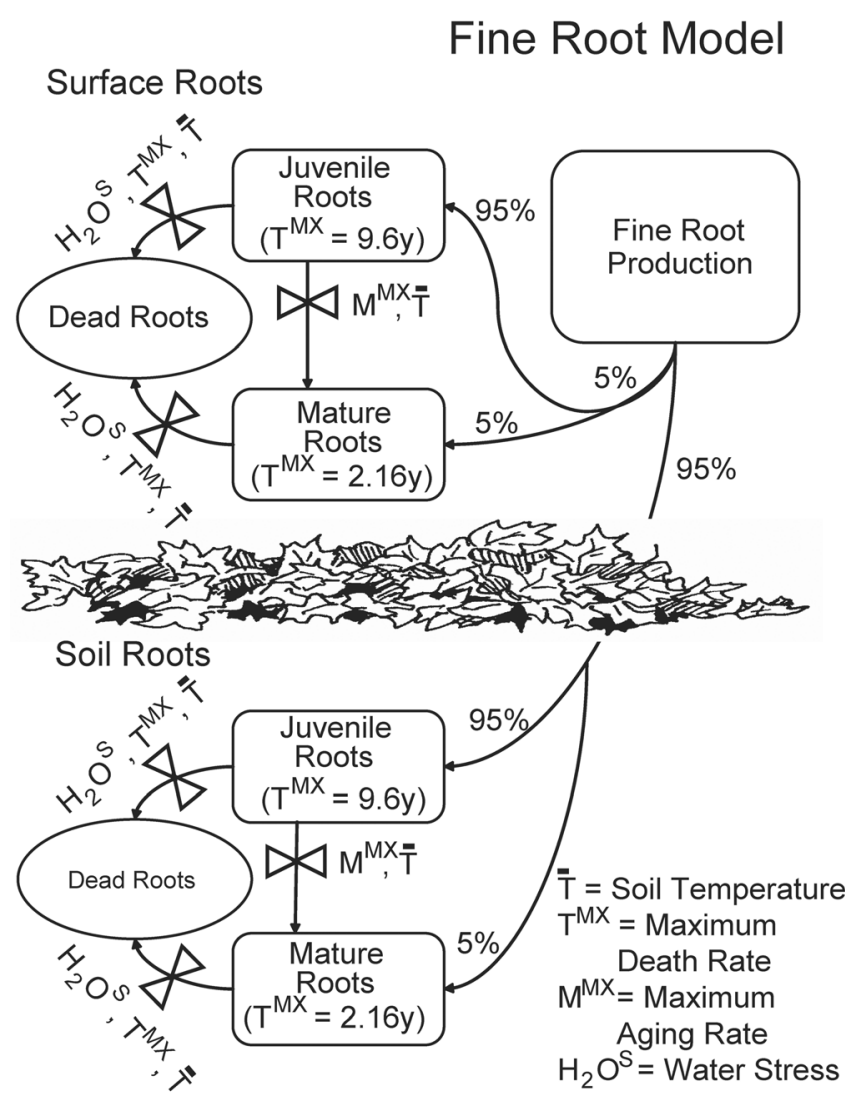

Figure 3. Fine root growth submodel used in the ForCent model. This model is based on the model developed by Parton et al. [1978]. 

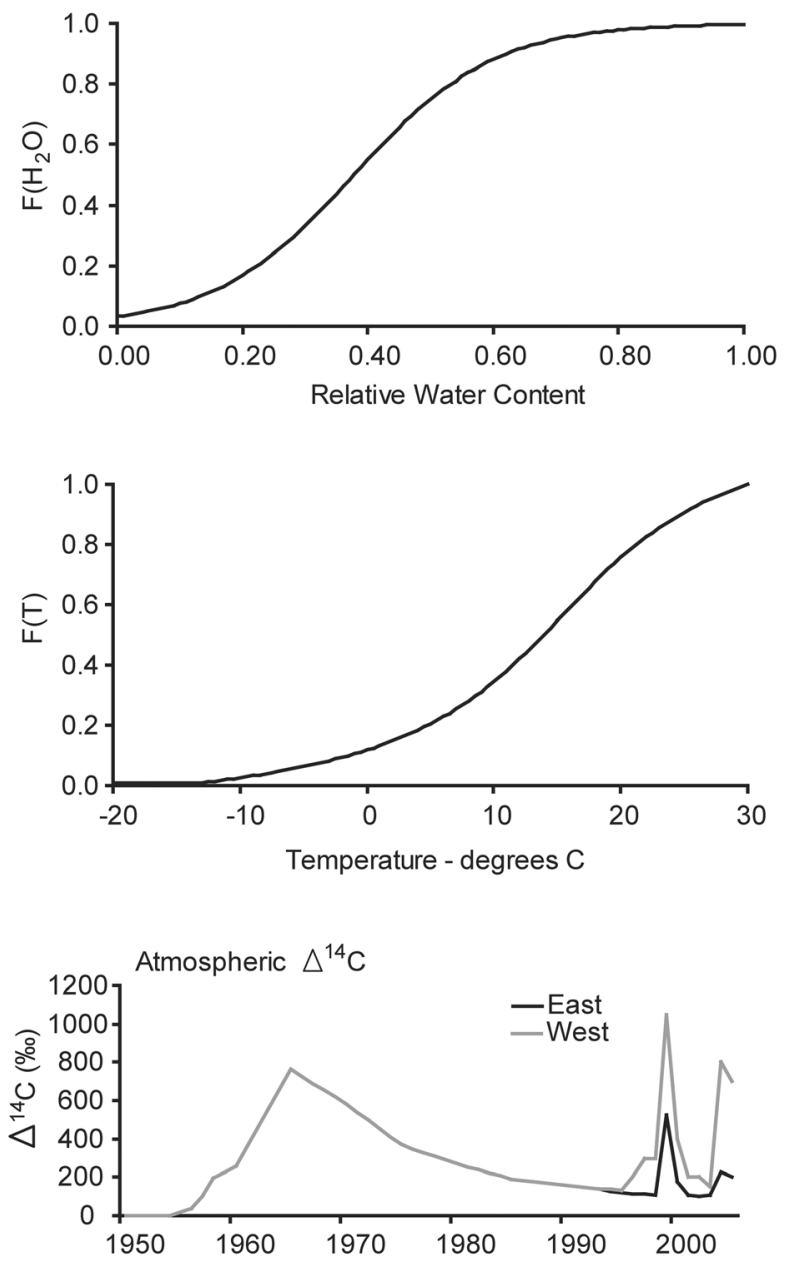

Figure 4. (a) Impact of soil relative water content $[\mathrm{F}(\mathrm{W})]$ on decomposition of ForCent soil pools; (b) the effect of soil temperature $[\mathrm{F}(\mathrm{T})]$ ) on the decomposition of soil pools; and (c) observed atmospheric $\Delta{ }^{14} \mathrm{C}$ levels from 1950 to 2005 for the east and west EBIS experimental sites. Atmospheric $\Delta{ }^{14} \mathrm{C}$ values for the east and west sites from 1995 to 2006 are based on observed average wood cellulose values for these sites.

are decreased if the carbohydrate pool is less than two times the maximum leaf carbon level. We also assume that the stored carbohydrate pool will not exceed five times the maximum leaf carbon level (carbon inputs to the stored carbohydrate are set equal to zero if the maximum level is exceeded). The assumption regarding the maximum level for stored carbohydrate pools is based on the concept that photosynthesis rates decrease if plant carbohydrate levels are too high, while low levels of stored carbohydrates reduce maintenance respiration.

[16] The ForCent model includes a dynamic carbon allocation scheme which assumes that fine root growth has first priority, followed by live leaves and wood growth. The plant growth model calculates the maximum plant growth rate as a function of air temperature, intercepted solar radiation, and water stress [Parton et al., 2001]. The model calculates the fraction of plant production going to fine root a. growth $(\mathrm{Fr})$ as a function of the water and nutrient stress using equation (2):

$$
\mathrm{Fr}=\operatorname{maximum}(\mathrm{F}(\mathrm{Ws}), \mathrm{F}(\mathrm{Ns}))
$$

where $\mathrm{F}(\mathrm{Ws})$ is the impact of water stress on Fr (increases linearly from 0.05 to 0.18 as water stress increases from the minimum value to the maximum value) and $\mathrm{F}(\mathrm{Ns})$ is the impact of nutrient stress on $\mathrm{Fr}$ (increases linearly from 0.05 to 0.18 as nutrient stress increases from the minimum value to the maximum value). The ratio of available nitrogen to plant nitrogen demand is used as the index for nutrient stress (ratio equal to one is associated with minimum nutrient stress), while the water stress term comes from the plant growth model. Fine root growth occurs during the time periods when net plant production is positive and during the first month of spring leaf out using the stored carbohydrate pool.

[17] Live leaf growth receives the remaining carbon and nutrients available for plant growth until the maximum live leaf area is attained. Maximum leaf area is specified for each plant type as a function of the aboveground wood biomass using an allometric function. Wood growth occurs after maximum leaf area is attained using the remaining available carbon and nutrients for wood growth. The model specifies the fraction of carbon promoting wood growth in various plant parts $(20 \%, 65 \%$, and $15 \%$ for fine branches, large c. wood, and coarse roots, respectively). Wood growth is assumed to occur during the first four months following spring leaf out. The plant phenology rules are based on Oak Ridge site data showing that maximum leaf area is attained a month after spring leaf out starts and that new wood growth starts after maximum leaf area is attained, but before the end of July. Initiation of spring leaf out starts after the weekly running average air temperature exceeds $10^{\circ} \mathrm{C}$ and leaf senescence occurs after the weekly running average air temperature drops below $7^{\circ} \mathrm{C}$.

\subsection{Enriched Background Isotope Study Computer Runs}

[18] The ForCent model was set up to simulate the Enriched Background Isotope Study experiments by running the model to equilibrium conditions using a 1900 year computer simulation that used observed daily weather data (1900-2005) and soil texture data as inputs to the model. In 1900 , the forest was clear-cut and then started to regrow. The ecosystem dynamics from 1900 to the present were simulated using the observed weather data from that time period. The Enriched Background Isotope Study model experiments for the east and west sites were started in 1995. The atmospheric $\Delta{ }^{14} \mathrm{C}$ levels taken from 1950 to 2005 (Figure 4c) show that they started to increase in the mid 1950s, peaked in the late 1960s, and have decreased since then. Locally, elevated atmospheric $\Delta{ }^{14} \mathrm{C}$ levels started to increase in 1995 for the west Enriched Background Isotope Study site, but did not start to increase until 1999 for the east site. These atmospheric $\Delta{ }^{14} \mathrm{C}$ values were assumed to be 0.0 before 1950. After 1995, the atmospheric $\Delta{ }^{14} \mathrm{C}$ values for the east and west sites were assumed to be equal to the observed yearly average of new wood cellulose $\Delta{ }^{14} \mathrm{C}$ values.

[19] The Enriched Background Isotope Study experiments were set up using four different model runs where low and high $\Delta{ }^{14} \mathrm{C}$ labeled leaves were added to both the east and 
west sites. We simulated the exclusion of ambient senescing leaves in the fall of 2000, 2001, and 2002 at all of the sites, and then simulated their replacement by the addition of fixed masses of ambient and high $\Delta{ }^{14} \mathrm{C}$ labeled leaves in May of 2001, and January of 2002 and 2003. The west site had enriched $\Delta{ }^{14} \mathrm{C}$ roots and soil $\mathrm{C}$ because of the elevated atmospheric $\Delta{ }^{14} \mathrm{C}$ levels, while the east site had background $\Delta{ }^{14} \mathrm{C}$ roots and soil $\mathrm{C}$ levels because of lower atmospheric $\Delta{ }^{14} \mathrm{C}$ levels (Figure $4 \mathrm{c}$ ).

\subsection{ForCent Model Calibration}

[20] The data sets used to calibrate the parameters of the ForCent model include the observed plant production data (by biomass pool) at the Oak Ridge National Laboratory from 1993 to 2000 [Hanson et al., 2003a], soil respiration data from 1993 to 2000 [Hanson et al., 2003b], and the observed Enriched Background Isotope Study soil carbon $\Delta{ }^{14} \mathrm{C}$ data from 2000 to 2005 for the surface litter, humus, and mineral soil layers $(0-30 \mathrm{~cm}$ depth). We used a twostep process to calibrate the ForCent model. The first step was to use the observed plant production and biomass data from the Oak Ridge site to determine parameters in the plant production submodel. Most of the plant production submodel parameters were estimated based on direct observations from this site. The observed plant production and ecosystem carbon levels of the major plant parts [Hanson et al., 2003b] were used to determine the maximum live leaf area, turnover rates, and allocation of carbon to the live fine root, branch, leaf, large wood, and coarse root pools. The maximum maintenance respiration rates are $3.4 \mathrm{yr}^{-1}$ and $3.1 \mathrm{yr}^{-1}$ for juvenile and mature roots, and were adjusted to match the total soil respiration rates observed at the Oak Ridge National Laboratory site [Hanson et al., 2003b]. The key assumption used for adjusting maintenance respiration rates is that modeled heterotrophic respiration rates have greater certainty compared to root maintenance respiration values. Maximum root death rates are $9.6 \mathrm{yr}^{-1}$ and $2.2 \mathrm{yr}^{-1}$ for juvenile roots and mature roots are parameterized so that total fine root biomass matched the Joslin et al. [2006] data set. This data set was also used to derive the fraction of carbon allocated to root growth in the mineral soil and humus layers $(95 \%$ and $5 \%$, respectively), the maximum fraction of juvenile roots transferred to mature roots $\left(1.5 \mathrm{yr}^{-1}\right)$, and the fraction of new root growth allocated to juvenile roots $(95 \%)$ and mature roots $(5 \%)$. Growth respiration rate is assumed to be $23.3 \%$ for all of the live plant parts [Hanson et al., 2003b]. The relative difference among the maximum maintenance respiration rates for live leaves, fine branches, large wood, and coarse roots was based on data from Ryan et al. [1996] showing that live leaves have the highest respiration rates and that wood respiration rates are more than one order of magnitude lower than live leaf respiration rates. Ecosystem nitrogen inputs were adjusted so that the observed mean annual production matched the observed data.

[21] The second step in the model calibration process was to use the observed time series $(1972-2004)$ of $\Delta{ }^{14} \mathrm{C}$ data for the mineral soil and humus layers to determine the mixing rate of humus material into the mineral soil layer, the maximum decay rates for the humus layer, and the soil mineral slow pool and passive soil organic matter pools. The model fitting process showed that the site specific best fit to mineral soil $\Delta{ }^{14} \mathrm{C}$ was to have $40 \%$ of the mineral soil organic matter in the slow pool for the west site and $55 \%$ for the east site. We used maximum turnover rates for the slow and passive soil organic matter so that $47 \%$ of the total soil organic matter was slow material in order to best fit the combined east and west mineral soil $\Delta{ }^{14} \mathrm{C}$ data. The maximum turnover rate of the humus, mineral slow pools, and soil passive pools, and mixing of the humus slow pool into the mineral soil layer, was estimated by finding parameters that resulted in the best fit (minimum root mean square error) to the observed soil and litter layer $\Delta{ }^{14} \mathrm{C}$ data. There is more uncertainty in these parameters since the observed soil $\Delta{ }^{14} \mathrm{C}$ data did not include direct measures of the turnover rates for the different soil organic matter pools.

[22] The notation section presents a list of the parameter values, including the definitions of the model parameters which were adjusted to best fit observed data from the Oak Ridge site. Numerous documents containing the information needed to reproduce the model results shown here, such as the version of the ForCent model used in this paper, the computer code, user manuals, definitions of all of the model parameters, guides on how to use the model, and weather data sets used to run the model, can be downloaded from the following web site: (http://www.nrel.colostate.edu/projects/ daycent/downloads.html).

\section{Results}

\subsection{ForCent Model Verification}

[23] From 1993 to 2000, model results compare favorably with observed mean plant production (Table 1). Both the model and the data show that leaf production does not vary substantially between years, while there are considerable year-to-year changes in fine root and wood plant production. The absolute mean error of annual leaf and total plant production are less than $10 \%$ of the mean annual production ( $6 \%$ and $9 \%$ ), while absolute mean error for wood production and fine root production are less than $20 \%$ of mean annual production (17\% and $15 \%)$. Year-to-year variability in live leaf, wood, and total production are reasonably well simulated with $\mathrm{r}^{2}$ values greater than $0.50\left(\mathrm{r}^{2}=0.61,0.60\right.$, and 0.53 ); however, yearly changes in fine root production are not as well simulated with $\mathrm{r}^{2}$ for fine roots less than 0.40 . A comparison of the current ForCent simulated annual plant production with results from earlier versions of the DayCent model show that the ForCent model does a better job of simulating year-to-year changes in annual plant production (earlier DayCent model had an $\mathrm{r}^{2}=0.15$ and absolute mean error of $181 \mathrm{~g} \mathrm{C} \mathrm{m}^{-2} \mathrm{yr}^{-1}$ for total plant production versus $\mathrm{r}^{2}=0.53$ and absolute mean error of 55.0 ForCent).

[24] Hanson et al. [2003b] developed a data-based soil respiration model for predicting daily soil respiration at the Oak Ridge National Laboratory site. The mean and range of the annual soil respiration from 1993 to 2000 for the Hanson and ForCent models (Table 1) are quite similar, the $\mathrm{r}^{2}$ for the ForCent and Hanson model comparison for annual soil respiration is quite high $\left(\mathrm{r}^{2}=0.77\right)$, and the absolute mean error between the two models is less than $6 \%$ of the mean annual soil respiration rate. A comparison of the Hanson and ForCent simulated daily soil respiration 
Table 1. Comparison of Observed and Simulated Plant Production for Leaves, Fine Roots, Total Wood Production, Total Production, and Soil Respiration From 1993 to 2000 at the Oak Ridge Site [Hanson et al., 2003a, 2003b] ${ }^{\mathrm{a}}$

\begin{tabular}{|c|c|c|c|c|}
\hline Annual Plant Production & $\begin{array}{l}\text { Simulated Mean } \\
\left(\mathrm{g} \mathrm{C} \mathrm{m}^{2} \mathrm{yr}^{-1}\right)\end{array}$ & $\begin{array}{l}\text { Observed Mean } \\
\left(\mathrm{g} \mathrm{C} \mathrm{m}^{-2} \mathrm{yr}^{-1}\right)\end{array}$ & $\begin{array}{l}\text { Mean Absolute Error } \\
\quad\left(\mathrm{g} \mathrm{C} \mathrm{m}^{-2} \mathrm{yr}^{-1}\right)\end{array}$ & $\begin{array}{c}\text { Model Versus Observed } \\
\text { Data }\left(\mathrm{r}^{2}\right)\end{array}$ \\
\hline Leaf & $246.0(230-249)$ & $240.0(233-258)$ & 14.0 & 0.61 \\
\hline Wood (branch + large wood + coarse roots) & $267.0(99-374)$ & $264.0(200-348)$ & 43.0 & 0.60 \\
\hline Fine roots & $116.0(67-136)$ & $113.0(89-153)$ & 17.0 & 0.38 \\
\hline Total production & $629.0(413-753)$ & $616.0(529-747)$ & 55.0 & 0.53 \\
\hline Soil respiration & $916.0(809-1024)$ & $941.0(808-976)$ & 52.0 & $0.77^{\mathrm{c}}$ \\
\hline
\end{tabular}

${ }^{a}$ Table 1 also contains the maximum and minimum annual flux values during the time period, the mean absolute error, and $\mathrm{r}^{2}$ values for the model versus observed data comparison.

${ }^{b}$ Mean absolute error where $\mathrm{Oi}$ is the observed value, $\mathrm{Si}$ is the simulated value, and $\mathrm{N}$ is the number of observations.

${ }^{c}$ Data from 1998 and 1999 were excluded because of uncertainty about which model was correct (see discussion in text).

results from the 1993 to 2000 shows that the results are quite similar for six years $\left(\mathrm{r}^{2}\right.$ range from 0.62 to 0.84$)$, while during two of those years (1998 and 1999), the comparisons are less favorable $\left(\mathrm{r}^{2}<0.50\right)$. Periods when the models do not agree occur when the ForCent model simulates lower soil respiration rates because of lower than normal juvenile root biomass and root production. Unfortunately, the limited observed daily soil respiration during those two years does not allow us to determine which model is more accurate. A comparison of the ForCent model predictions of daily soil respiration with the previous forest DayCent model underestimated soil respiration on days with precipitation which resulted in a $50 \%$ to $100 \%$ underestimate of soil respiration when observed respiration is $>4 \mathrm{~g} \mathrm{C} \mathrm{m}^{-2} \mathrm{~d}^{-1}$.

[25] Patterns for $\Delta{ }^{14} \mathrm{C}$ of the surface litter, humus, and the $0-30 \mathrm{~cm}$ mineral layers for the enriched and nearbackground litter addition treatments (Figures 5 and 6 and Table 2) show a general agreement between the model results and observed data. The model and data show that the $\Delta{ }^{14} \mathrm{C}$ content of the surface litter layer (Figure 5) is higher for the west site compared to the east site, and that the nearbackground litter treatment has lower $\Delta{ }^{14} \mathrm{C}$ content compared to the enriched treatment. The overall fit of the model to the observed data is similar for both the east and west sites, and the mean absolute error (Table 2) ranges from $27 \mathrm{~g} \mathrm{C} \mathrm{m}^{-2}$ for the east site low treatment to $52 \mathrm{~g} \mathrm{C} \mathrm{m}^{-2}$ for the west site low treatment. The higher surface litter $\Delta{ }^{14} \mathrm{C}$ content of the west site compared to the east site reflects the higher atmospheric $\Delta{ }^{14} \mathrm{C}$ content of the west site (Figure 4a).

[26] A comparison of observed and simulated $\Delta{ }^{14} \mathrm{C}$ of the humus layer (Figures $5 \mathrm{c}$ and $5 \mathrm{~d}$ ) shows increased $\Delta{ }^{14} \mathrm{C}$ levels for enriched litter additions. The ForCent simulations for the west site capture the $\Delta{ }^{14} \mathrm{C}$ increase of the humus layer beginning in 1999, following the large atmospheric $\Delta{ }^{14} \mathrm{C}$ exposures (see Figure $4 \mathrm{a}$ ). This contrasts with the simulated humus $\Delta{ }^{14} \mathrm{C}$ levels in the east site which decrease until 2000, and then stabilize around $190 \%$ o for ambient plots with near-background litter additions. The model results compare well, yet the results from the east site are more consistent with fewer discrepancies. The absolute mean errors are much lower for the high and low treatments for the east site (21 and $8 \mathrm{~g} \mathrm{C} \mathrm{m}^{-2}$ ) compared to the west site (53 and $85 \mathrm{~g} \mathrm{C} \mathrm{m}^{-2}$ ). This pattern of better fit of the model to observed data from the east site is true for both the humus layer and the surface litter layer. The major discrepancy for
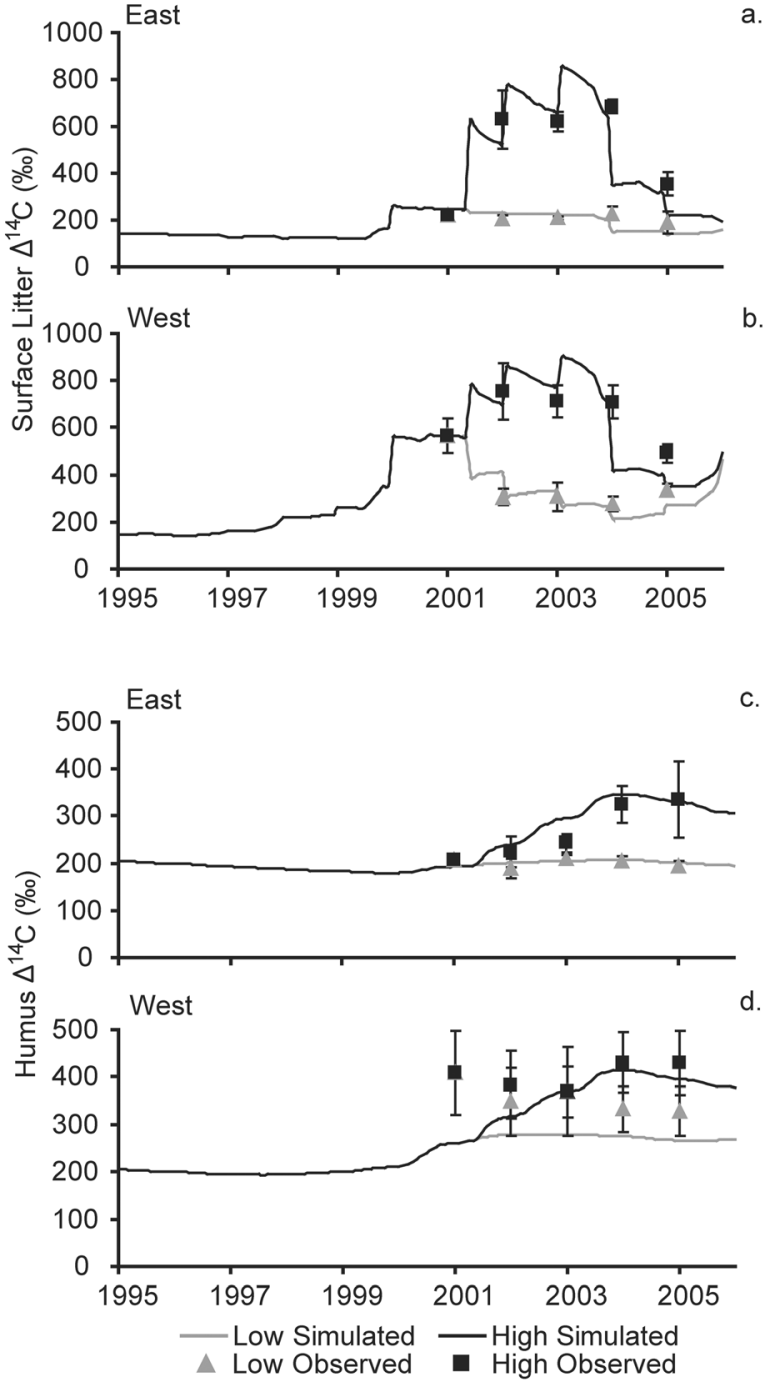

Figure 5. Simulated versus observed $\Delta{ }^{14} \mathrm{C}$ content of the surface litter layer for the (a) east and (b) west sites. Simulated versus observed $\Delta{ }^{14} \mathrm{C}$ content of the humus layer for the (c) east and (d) west EBIS sites. Data are presented for both the low and high litter treatments in addition to the standard deviation of the observed data. 

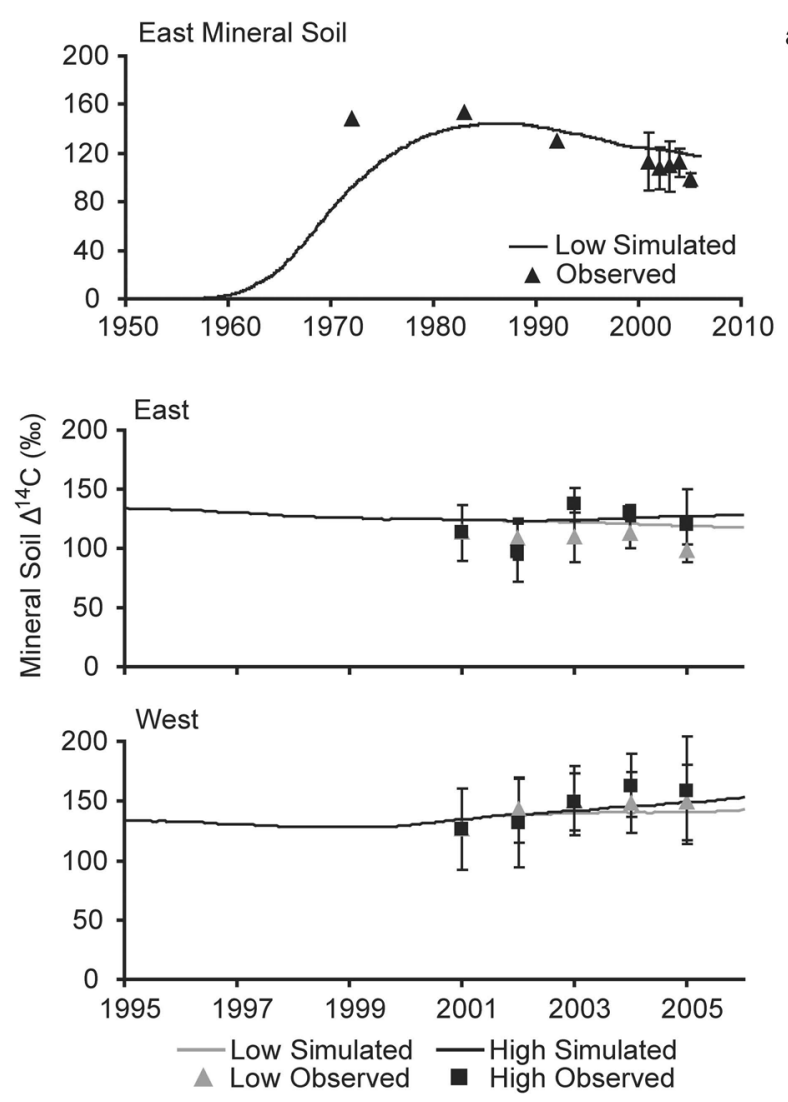

Figure 6. Simulated versus observed mineral soil layer $\Delta{ }^{14} \mathrm{C}$ content for the (a) low east site from 1950 to 2005; (b) low and high east site mineral soil $\Delta{ }^{14} \mathrm{C}$ values from 1995 to 2005; and (c) west site (high and low treatments) mineral soil $\Delta{ }^{14} \mathrm{C}$ values from 1995 to 2005 . Data from the $\Delta{ }^{14} \mathrm{C}$ levels prior to 2001 came from the Walker branch site, and standard deviation of the observed data is plotted.

the humus layer is an underestimate of the west site $\Delta{ }^{14} \mathrm{C}$ value for 2001. It was impossible to adjust the maximum turnover rate of the humus layer to fit both the 2001 point and the observations from 2002 to 2005 .

[27] A comparison of the observed and simulated soil mineral $\Delta{ }^{14} \mathrm{C}(0-30 \mathrm{~cm}$ soil depth) values from 1950 to 2005 (Figure 6a) for the low east site shows that the soil $\Delta{ }^{14} \mathrm{C}$ values peaked from 1975 to 1985 , and then started to decrease. The major discrepancy is the model underestimate of the soil $\Delta{ }^{14} \mathrm{C}$ in 1973 which is likely a result from the fact that the observed $1973 \Delta{ }^{14} \mathrm{C}$ value is for the 0-15 cm depth (simulated 0-30 cm depth soil includes older soil that has not been impacted by the recent increases in atmospheric $\Delta{ }^{14} \mathrm{C}$ bomb carbon). Model results for the east site show a continuing pattern of decreasing $\Delta{ }^{14} \mathrm{C}$ values for both litter addition treatments from 1995 to 2005 (Figure 6b). This contrasts with the west site results after 1999 where increases in soil $\Delta{ }^{14} \mathrm{C}$ are observed and simulated (Figure 6b). The observed data is consistent with simulations showing higher soil $\Delta{ }^{14} \mathrm{C}$ values for the west site compared to the east site, and higher values of $\Delta{ }^{14} \mathrm{C}$ by 2005 for the enriched litter treatment. The observed versus simulated mean absolute error for the mineral soil $\Delta{ }^{14} \mathrm{C}$ values in the high and low treatments in the west site is lower ( 10 and $\left.8 \mathrm{~g} \mathrm{C} \mathrm{m}^{-2}\right)$ compared to the east site (12 and $\left.14 \mathrm{~g} \mathrm{C} \mathrm{m}^{-2}\right)$. The biggest model discrepancy is an underestimate of the east site low treatment humus $\Delta{ }^{14} \mathrm{C}$. The standard deviation for the observed mineral soil $\Delta{ }^{14} \mathrm{C}$ data is quite high for both sites.

\subsection{Model Validation Comparisons}

[28] The Enriched Background Isotope Study soil respiration $\Delta{ }^{14} \mathrm{C}$ data for the mineral soil, humus, and surface litter layers, and for total soil respiration, along with the dead and live root $\Delta{ }^{14} \mathrm{C}$ data, were not used in the model calibration process, and as a result, could be used to validate model predictions. A comparison of the observed versus simulated $\Delta{ }^{14} \mathrm{C}$ values for the live and dead roots for the east and west sites (Figure 7) generally agree with higher $\Delta{ }^{14} \mathrm{C}$ values for the dead and live roots in the west site, and a pattern of decreasing $\Delta{ }^{14} \mathrm{C}$ values from 1999 until 2004 for both sites. The elevated $\Delta{ }^{14} \mathrm{C}$ values after 2004 are due to increased atmospheric $\Delta{ }^{14} \mathrm{C}$ for both the east and west sites (higher increases in the west site). A comparison of the simulated live juvenile root $\Delta{ }^{14} \mathrm{C}$ values with the new root growth screen data (Figure $7 \mathrm{c}$, root biomass that grows in screens inserted into the soil) shows that the model correctly predicts the observed decreases in $\Delta{ }^{14} \mathrm{C}$ values following the 1999 atmospheric labeling events; higher $\Delta{ }^{14} \mathrm{C}$ values for the west site compared to the east site, and the observed increase in $\Delta{ }^{14} \mathrm{C}$ values in 2004 and 2005. The major discrepancy is an overestimate of live (total root biomass and juvenile roots) and dead root $\Delta{ }^{14} \mathrm{C}$ values by the model for the west site from 2001 to 2004 .

Table 2. Comparison of the Observed and Simulated Mean $\Delta{ }^{14} \mathrm{C}$ for Surface Litter, Humus, and Mineral Soil for the East and West Sites and High and Low Treatments ${ }^{\mathrm{a}}$

\begin{tabular}{lccc}
\hline & $\begin{array}{c}\text { Observed Mean } \\
\Delta{ }^{14} \mathrm{C}(\%)\end{array}$ & $\begin{array}{c}\text { Simulated Mean } \\
{ }^{14} \mathrm{C}(\%)\end{array}$ & $\begin{array}{c}\text { Mean Absolute } \\
\text { Error }^{\mathrm{b}}\end{array}$ \\
\hline East & & Surface Litter & \\
$\quad$ High & 503.0 & & \\
Low & 211.0 & 478.0 & 52.0 \\
West & & 211.0 & 27.0 \\
$\quad$ High & 646.0 & 628.0 & 42.0 \\
Low & 358.0 & 361.0 & 48.0 \\
East & & Humus & \\
High & 266.0 & 200.0 & 21.0 \\
Low & 200.0 & 201.0 & 8.0 \\
West & & & \\
High & 405.0 & 351.0 & 53.0 \\
Low & 357.0 & 272.0 & 85.0 \\
Soil East & & Carbon & \\
High & 119.0 & 125.0 & 12.0 \\
Low & 108.0 & 122.0 & 14.0 \\
Soil West & & & 10.0 \\
High & 146.0 & 142.0 & 8.0 \\
Low & 143.0 & 139.0 & \\
\hline
\end{tabular}

${ }^{\mathrm{a}}$ The mean absolute error for the surface litter, humus, and mineral soil

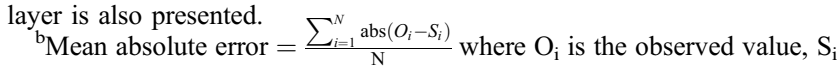
is the simulated value, and $\mathrm{N}$ is the number of observations. 

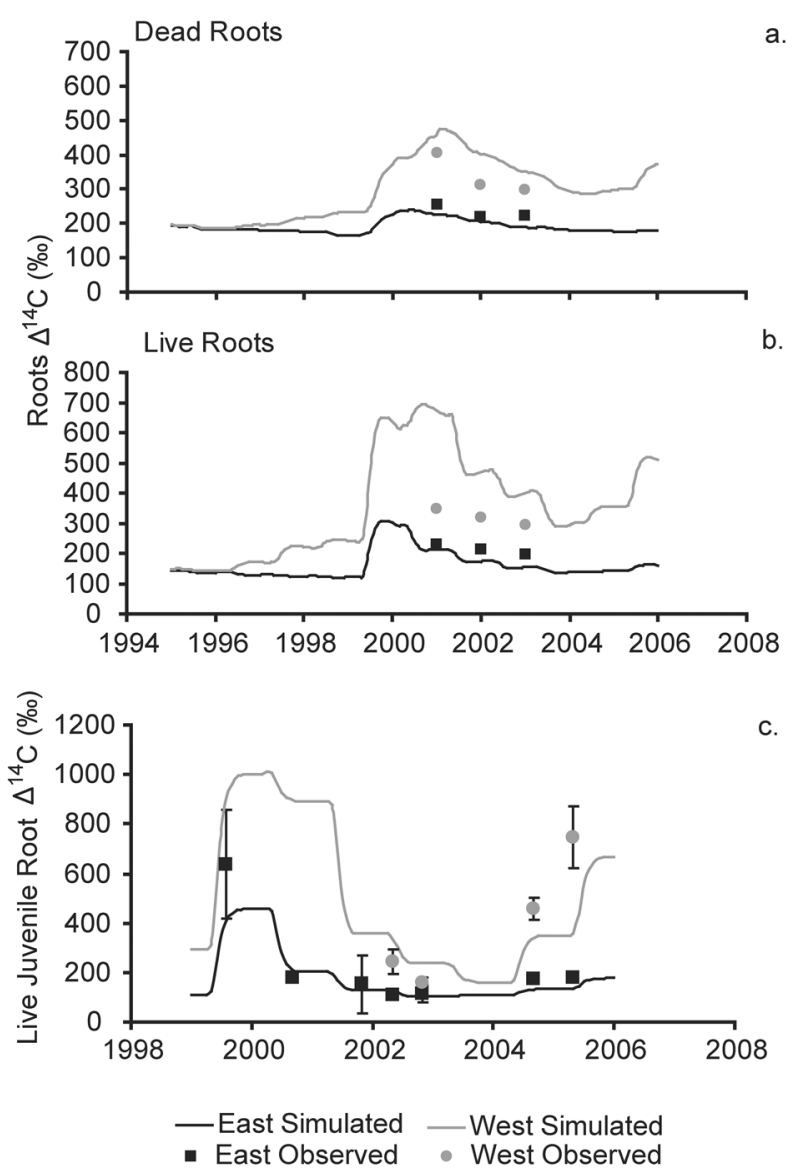

Figure 7. Simulated versus observed $\Delta{ }^{14} \mathrm{C}$ levels for the (a) dead roots in the east and west sites; (b) live roots in the east and west sites; and (c) a comparison of simulated $\Delta{ }^{14} \mathrm{C}$ values for live juvenile roots with the observed root screen new root growth $\Delta{ }^{14} \mathrm{C}$ data for the east and west sites (plus the standard deviation of the observed data).

[29] Simulated total soil respiration and $\Delta{ }^{14} \mathrm{C}$ values for the west site during August 2003 (Figure 8) show large day-to-day changes in total soil respiration and spikes in the $\Delta{ }^{14} \mathrm{C}$ values for the high ${ }^{14} \mathrm{C}$ litter treatments associated with rainfall events. These results are consistent with the data from Cisneros-Dozal et al. [2007] showing a $50-100 \%$ increase in soil respiration $\Delta{ }^{14} \mathrm{C}$ values following rainfall events for the high treatments and minimal changes in $\Delta{ }^{14} \mathrm{C}$ of soil respiration following rainfall events for the low treatments. Increases in the $\Delta{ }^{14} \mathrm{C}$ of soil respiration following rainfall events for the high treatments are caused by rainfall-induced increased decomposition of the highly labeled surface litter layer (surface litter and humus layers).

[30] A comparison of the observed versus simulated $\Delta{ }^{14} \mathrm{C}$ soil respiration values for all of the soil pools and different treatments (Figure 9) shows that the model performed well, representing the observed data set $\left(r^{2}=0.75\right)$. Simulated mean mineral soil respiration $\Delta{ }^{14} \mathrm{C}$ values (Figure 9a) follow a pattern of higher $\Delta{ }^{14} \mathrm{C}$ levels in the east site; however, the model tends to underestimate the observed increase in $\Delta{ }^{14} \mathrm{C}$ levels for the high versus low treatments at both the east and west sites. Our results suggest that the model underestimated the amount of labeled aboveground litter dissolved organic carbon transported to the mineral soil layer, and lost as soil respiration from the mineral soil layer. Simulated and observed 2001 soil respiration $\Delta{ }^{14} \mathrm{C}$ values for the surface litter and humus layers (Figure $9 \mathrm{~b}$ ) follow the general pattern of higher values for the west site, and an increase in $\Delta{ }^{14} \mathrm{C}$ levels with the high treatment. The model tends to underestimate the humus layer $\Delta{ }^{14} \mathrm{C}$ content and also appears to be underestimating the amount of the elevated $\Delta{ }^{14} \mathrm{C}$ material that is transferred to the humus layer for the west site.

\subsection{Sensitivity Analysis}

[31] The model tuning process revealed that results are sensitive to the assumed values of the atmospheric $\Delta{ }^{14} \mathrm{C}$ values on the east and west sites, and also to the fraction of the mineral soil organic matter in the passive pool (Figure 1). We assumed that the atmospheric $\Delta{ }^{14} \mathrm{C}$ values for the east and west sites were equal to the observed $\Delta{ }^{14} \mathrm{C}$ values of new wood cellulose. Observed atmospheric $\Delta{ }^{14} \mathrm{C}$ values for the east and west sites were measured from 2001 to 2005 , showing variability both within the year and among different years. The impact of changing the atmospheric $\Delta{ }^{14} \mathrm{C}$ values by $\pm 30 \%$ after 1995 on simulated mineral soil $\Delta{ }^{14} \mathrm{C}$ values (Figures 10a and $10 \mathrm{~b}$ ) shows that the model best fit the west site observed soil $\Delta{ }^{14} \mathrm{C}$ values for the high and low treatments with a $30 \%$ increase in atmospheric $\Delta{ }^{14} \mathrm{C}$ levels. Similar results are also found for the simulated $\Delta{ }^{14} \mathrm{C}$ values for the humus layer (data not
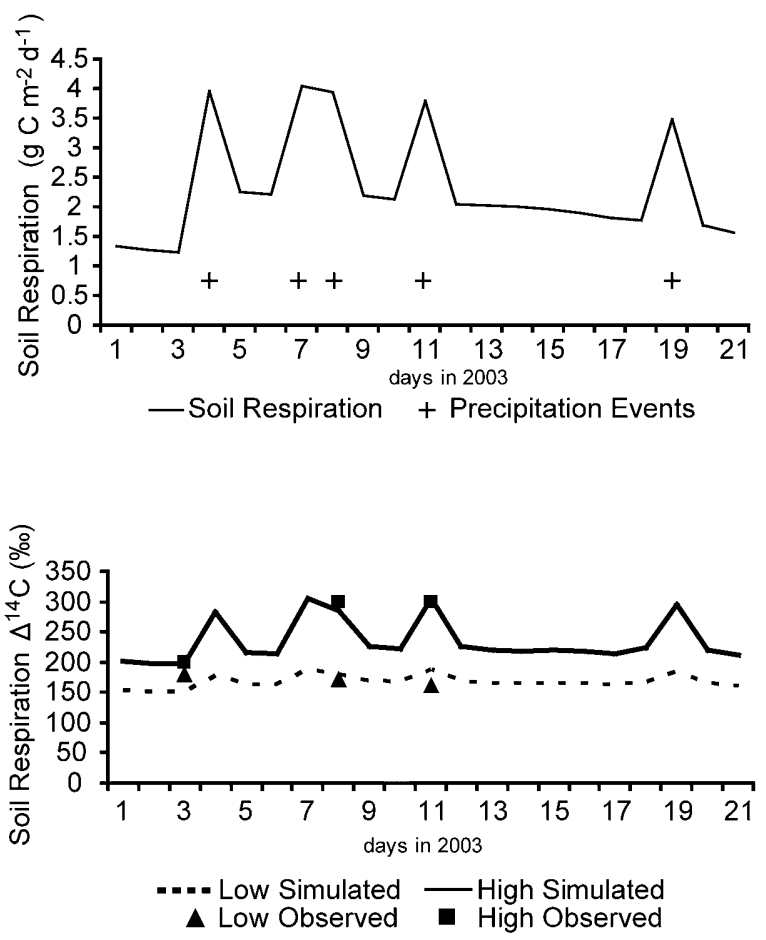

Figure 8. (a) Simulated total soil respiration from August 2003 in response to rainfall events; and (b) observed versus simulated $\Delta{ }^{14} \mathrm{C}$ of total soil respiration for the high and low treatments at the east site [Cisneros-Dozal et al., 2007]. 

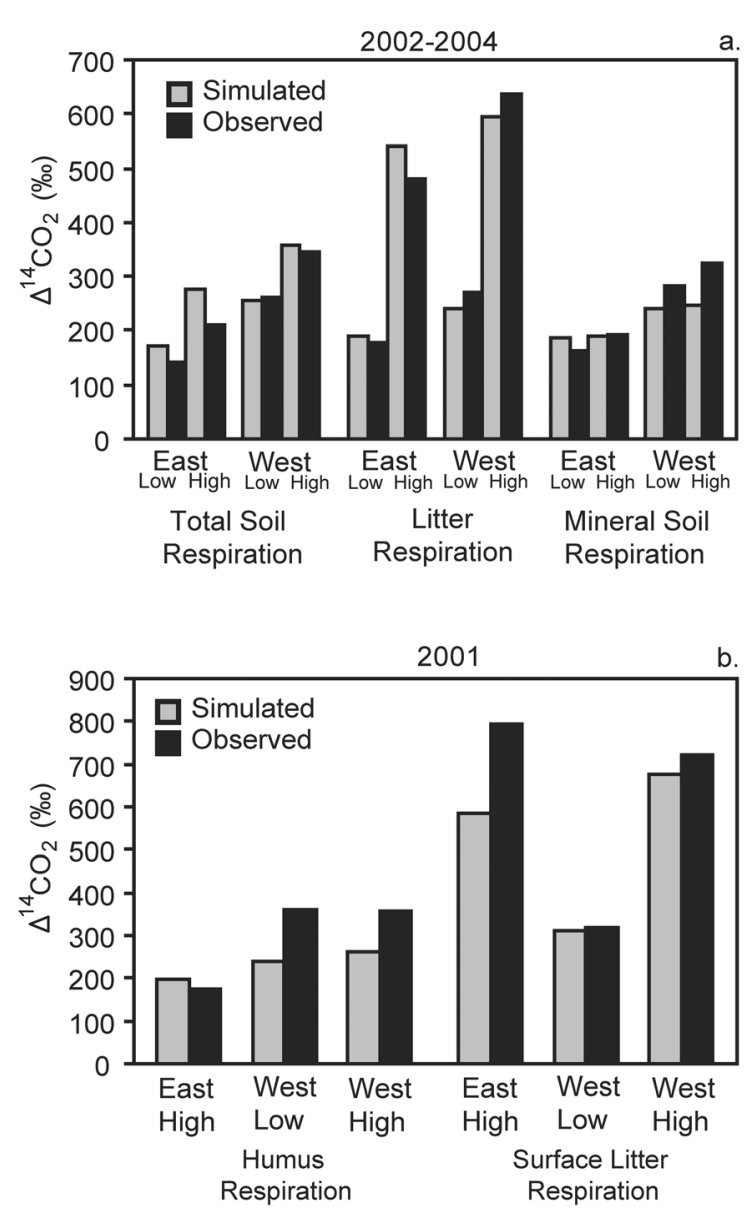

Figure 9. Comparison of observed and simulated average $\Delta{ }^{14} \mathrm{C}$ values for total soil respiration, litter respiration (surface litter plus humus layers), and mineral soil respiration from 2002 to 2004 for (a) east and west site high and low treatments; and (b) average humus and surface litter $\Delta{ }^{14} \mathrm{C}$ respiration from the east and west site high and low treatments for 2001 .

presented) in the high and low treatment model runs for the west site, thus suggesting that the mean atmospheric $\Delta{ }^{14} \mathrm{C}$ values were underestimated by the cellulose $\Delta{ }^{14} \mathrm{C}$ values in the west site. Unfortunately, model results for the simulated live and dead roots in the east site do not agree with these results since elevating the atmospheric $\Delta{ }^{14} \mathrm{C}$ values by $30 \%$ increased the simulated overestimate of the live and dead root $\Delta{ }^{14} \mathrm{C}$ values (data not shown). Results for the east site (Figures 10c and 10d) show that the best model results for the mineral soil $\Delta{ }^{14} \mathrm{C}$ values occur with a $30 \%$ reduction in atmospheric $\Delta{ }^{14} \mathrm{C}$ values.

[32] The best fit estimate of the fraction of mineral soil organic matter in the passive fraction for combined east and west sites was $47 \%$. We kept the total mineral soil organic matter fixed and altered the decay rates of slow and passive pools in order to set up computer model runs with $40 \%$ and $55 \%$ passive soil organic matter. Results for the east site (Figures 11a and 11b) showed that the best fit to the observed mineral soil $\Delta{ }^{14} \mathrm{C}$ data was obtained with $55 \%$ passive soil organic matter. The improved fit to the observed data was clearest for the east site low treatment where the model overestimated the observed soil $\Delta{ }^{14} \mathrm{C}$ values. Opposite results were observed for the west site where the $40 \%$ passive run was best fit to the observed high and low mineral soil $\Delta{ }^{14} \mathrm{C}$ values.

\section{Discussion}

[33] We demonstrate here that the ForCent model can successfully simulate carbon dynamics of deciduous forest systems. Model results were compared with observed plant production data, carbon in the soil and plant pools, and $\Delta{ }^{14} \mathrm{C}$ dynamics for plants and soils during the Enriched Background Isotope Study experiment. Data from the Oak Ridge National Laboratory site was used to make major changes to the ForCent model and calibrate some of the

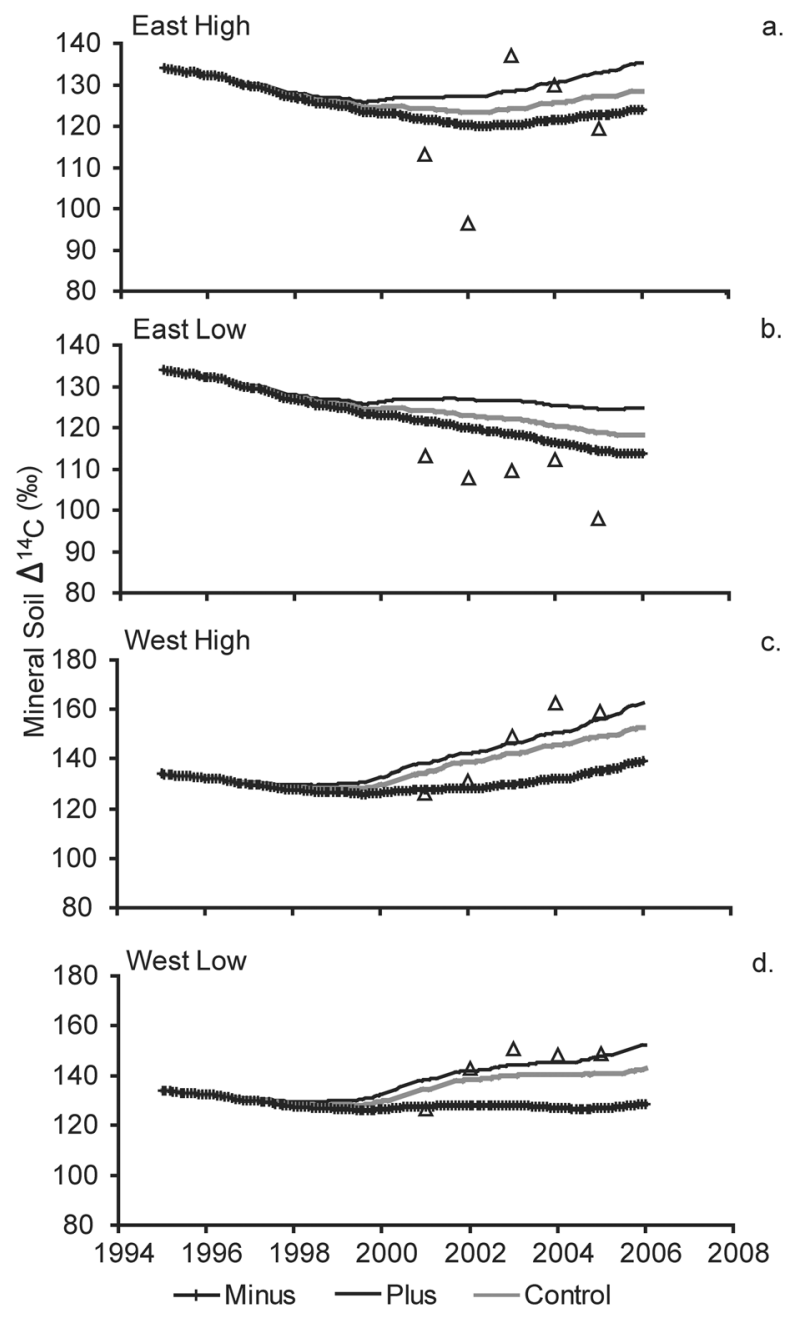

Figure 10. Comparison of observed and simulated mineral soil $\Delta{ }^{14} \mathrm{C}$ values for the control runs, and $\pm 30 \%$ atmospheric $\Delta{ }^{14} \mathrm{C}$ runs for the (a) east high treatment; (b) east low treatment; (c) west high treatment; and (d) west low treatment. Control atmospheric $\Delta{ }^{14} \mathrm{C}$ values for the east and west sites from 1995 to 2006 were assumed to be equal to the average new cellulose wood growth $\Delta{ }^{14} \mathrm{C}$ values in the east and west sites. 


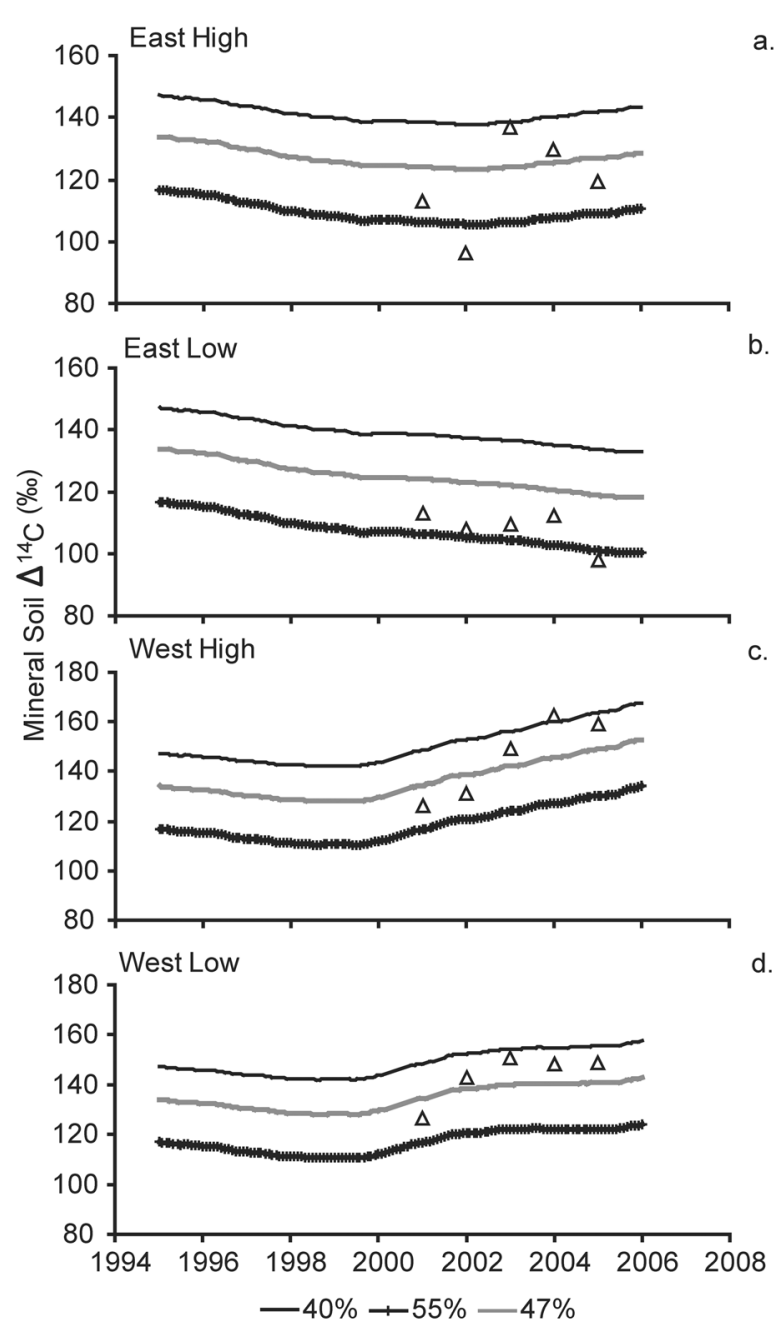

Figure 11. Comparison of the observed and simulated mineral soil $\Delta{ }^{14} \mathrm{C}$ values for the $47 \%$ passive SOM pool run, $40 \%$ passive SOM pool run, and 57\% passive SOM pool run for the (a) east high treatment; (b) east low treatment; (c) west high treatment; and (d) west low treatment.

parameters. The major improvements in the model include adding a detailed root growth model, a dynamic plant carbon allocation scheme, a surface humus layer, plant phenology in the plant production submodel, including a rainfall pulse response to the surface litter decay, and adding a plant stored carbohydrate pool. A comparison of the earlier DayCent model results show that the new ForCent model greatly improved the ability of the model to simulate year to year changes in forest plant production (total plant production $\mathrm{r}^{2}$ increased from 0.19 to 0.52 ). The process of adding plant phenology and seasonal patterns in wood growth (wood growth ceases at the end of July) resulted in a decrease in the simulated interannual variability of plant production, consistent with the observed interannual production data [Hanson et al., 2003a]. Stopping wood growth at the end of July results in plant storage of soil nutrients from August to October, and then utilized during the next growing season.
[34] One of the major improvements in the ForCent model was to include the precipitation pulse event multiplier for the surface litter decay based on the Hanson et al. [2003a] data-based soil respiration model. Comparison of the Hanson- and ForCent-simulated daily soil respiration rates, taken from 1993 to 2000 for the Oak Ridge National Laboratory site, showed close agreement with the observed data for both models $\left(r^{2}=0.61\right.$ and 0.64). Comparison of the daily simulated soil respiration for the Hanson and ForCent models for six of the eight years was quite good $\left(\mathrm{r}^{2}\right.$ ranging from 0.72 to 0.84 ). The ForCent model predicted lower soil respiration compared to the Hanson model during two of the years when ForCent predicted lower than average live root biomass and root production. Lower total soil respiration simulated by ForCent during these time periods resulted from reduced autotrophic respiration (maintenance plus growth) from the live roots. Root dynamics in the ForCent model are quite dynamic and respond to year-to-year differences in plant production and water stress, while the Hanson model assumed root growth patterns were less dynamic. It is not clear which model is correct since we did not have sufficient observed data during the time periods when the major ForCent and Hanson model differences were observed.

[35] The ForCent model correctly simulated higher $\Delta{ }^{14} \mathrm{C}$ levels for the surface litter and mineral soil pools in the west site, higher $\Delta{ }^{14} \mathrm{C}$ levels for the high labeled litter treatment, and also the incorporation of highly labeled leaf litter into the humus layer. Simulated results for the west site showed lower $\Delta{ }^{14} \mathrm{C}$ levels for mineral soil and humus layers compared to the observed data and suggest that the atmospheric $\Delta{ }^{14} \mathrm{C}$ levels for the west site might be underestimated. A sensitivity analysis suggests that increasing the assumed atmospheric $\Delta{ }^{14} \mathrm{C}$ levels from 1995 to 2005 results in an improved fit of the model results for the mineral soil and humus layer $\Delta{ }^{14} \mathrm{C}$ levels for the west site. The results from the observed and simulated west site root $\Delta{ }^{14} \mathrm{C}$ data suggest that west site atmospheric $\Delta{ }^{14} \mathrm{C}$ should be decreased and thus are inconsistent with mineral soil $\Delta{ }^{14} \mathrm{C}$ data. Results from the east site show that decreasing the atmospheric $\Delta{ }^{14} \mathrm{C}$ level results in a better fit to the observed mineral soil $\Delta{ }^{14} \mathrm{C}$ levels.

[36] The model fitting process and sensitivity analysis revealed that it is possible to correctly simulate the observed temporal changes in the mineral soil $\Delta{ }^{14} \mathrm{C}$ values during the last 50 years using different assumptions about the fraction of the total mineral soil carbon in the passive soil organic matter pool $(40-55 \%)$. We chose to fit the model using $47 \%$ since the best fit for the passive fractionation for the west site was $55 \%$ and was $40 \%$ for the east site. The new estimates of the turnover rates for slow and passive soil organic matter are different from the original Century model estimates [Parton et al., 1987], with the decay rate for passive soil organic matter decreased by $50 \%$ and the slow decay rate increased by $100 \%$ compared to the original values. Falloon et al. [1998] fit the RothC model to a similar data set at the Rothamsted site in England and assumed that the passive fraction (inert fraction in RothC) was only $10 \%$ of the soil organic matter pool. Petersen et al. [2005a, $2005 \mathrm{~b}$ ] used the CN-SIM model to simulate the changes in the mineral soil $\Delta{ }^{14} \mathrm{C}$ values during the last 50 years at three sites in Europe, and found that equally good fits to 
the observed data were between $10 \%$ and $50 \%$ of mineral soil organic matter in the inert fraction. A comparison of the results from the RothC, CN-SIM, and ForCent models shows that the peak mineral soil $\Delta{ }^{14} \mathrm{C}$ values occurred from 1975 to 1985 and had a similar temporal pattern during the last 50 years (increasing after 1957 and then decreasing after 1985). The results from the three different models show that there is considerable uncertainly in our estimates of the fraction of total mineral soil $\mathrm{C}$ in passive soil organic matter and in the decay rates of the slow and passive (or inert) pools.

[37] Observed differences between the high and low treatment mineral soil $\Delta{ }^{14} \mathrm{C}$ values show a slight increase for the high treatments. This increase is difficult to measure because of the large amount of carbon in the $0-15 \mathrm{~cm}$ soil layer, and suggests that our estimate of the mixing rate of humus material into the mineral soil layer is not well bounded. We are starting a new multisite ${ }^{14} \mathrm{C}$ surface litter layer experiment which will allow us to better quantify this flux since we will be measuring the $0-5 \mathrm{~cm}$ mineral soil layer instead of the $0-15 \mathrm{~cm}$ layer used in the Enriched Background Isotope Study experiment. Future resampling of the of the $\Delta{ }^{14} \mathrm{C}$ values of the humus and mineral soil layers from the Enriched Background Isotope Study experimental plots will also provide data to better quantify the mixing rate of humus material into the mineral soil.

[38] We used the observed Enriched Background Isotope Study $\Delta{ }^{14} \mathrm{C}$ data for live and dead fine root and soil respiration, surface litter, and layers to validate ForCent simulations (data not used for model calibration) of the movement of ${ }^{14} \mathrm{C}$ into the soil pools. ForCent correctly simulated the observed higher $\Delta{ }^{14} \mathrm{C}$ values for live and dead roots in the west site and also the general pattern of decreasing $\Delta{ }^{14} \mathrm{C}$ values following the 1999 exposure to elevated ${ }^{14} \mathrm{C}$ atmospheric levels. However, the model did tend to overestimate the $\Delta{ }^{14} \mathrm{C}$ values for live roots in the west site. The sensitivity analysis showed that increasing the atmospheric $\Delta{ }^{14} \mathrm{C}$ values in the west site improved the fit of the model to the humus and mineral soil $\Delta{ }^{14} \mathrm{C}$ values. This increase caused the model to exaggerate the existing overestimate of the live and dead root $\Delta{ }^{14} \mathrm{C}$ values for the west site.

[39] A comparison of the observed versus simulated soil respiration $\Delta{ }^{14} \mathrm{C}$ values shows that the model correctly simulated the major Enriched Background Isotope Study treatment differences and the movement of $\Delta{ }^{14} \mathrm{C}$ labeled leaf and root carbon into soil organic matter pools (observed versus simulated $r^{2}=0.75$ overall). The model tended to underestimate the observed increase in mineral soil respiration $\Delta{ }^{14} \mathrm{C}$ values for the high labeled litter treatments. This could result from an underestimate of the amount of labile surface litter material leaching out of the surface litter layer into the mineral soil layer and then quickly lost due to microbial respiration. Dissolved organic carbon flux measurements for the Enriched Background Isotope Study experiment [Fröberg et al., 2007, 2009] show that a substantial amount of dissolved organic carbon is leached out of the surface litter layer (surface litter, humus layers) into the mineral soil layer and quickly lost as soil respiration. These data from Fröberg et al. [2009] are currently being used to develop a new dissolved organic carbon leaching submodel in ForCent.

\section{Notation}

[40] This list includes the parameters and input variables which were adjusted to represent the dynamics of the deciduous forest system at Oak Ridge. An asterisk next to the parameter indicates that observed data from the site was used to determine the parameter. The procedure used to determine the parameter is described in the model parameterization section in the paper. A " 1 " next to the parameter indicates that the soil $\triangle{ }^{14} \mathrm{C}$ data for surface litter, humus, and mineral soil layers from the EBIS experiment were used to determine the parameter values by minimizing the root mean squared error between the observed and simulated EBIS $\Delta{ }^{14} \mathrm{C}$ data set. Model parameter values were not adjusted for most of the parameters. A complete list of the model parameter values, definitions of model parameters, ForCent model code, the input values used to run the model simulations, user documents, and information needed to run all of the model runs presented in the paper can be downloaded on our web site: (http://www.nrel.colostate.edu/projects/ daycent/downloads.html).

Fixed parameters file "fix.100"

Dec1 (1) maximum surface structural decomposition rate, the fraction of the
pool that turns over each year $\left(2.5 \mathrm{yr}^{-1}\right)$.

Dec1 (2) maximum soil structural decomposition rate, the fraction of the pool that turns over each year $\left(4.9 \mathrm{yr}^{-1}\right)$.

Dec2 (1) maximum surface metabolic decomposition rate, the fraction of the pool that turns over each year $\left(10.0 \mathrm{yr}^{-1}\right)$.

Dec2 (2) maximum soil metabolic decomposition rate, the fraction of the pool that turns over each year $\left(18.5 \mathrm{yr}^{-1}\right)$.

Dec3 (1) maximum decomposition rate of surface organic matter with active turnover, the fraction of the pool that turns over each year $\left(7.0 \mathrm{yr}^{-1}\right)$.

Dec3 (2) maximum decomposition rate of soil organic matter with active turnover, the fraction of the pool that turns over each year $\left(11.0 \mathrm{yr}^{-1}\right)$.

Dec $4^{1} \quad$ maximum decomposition rate of soil organic matter with slow turnover, the fraction of the pool that turns over each year $\left(0.0025 \mathrm{yr}^{-1}\right)$.

Dec5 $(1)^{1} \quad$ maximum decomposition rate of surface organic matter with intermediate turnover, the fraction of the pool that turns over each year $\left(0.16 \mathrm{yr}^{-1}\right)$. 
$\operatorname{Dec} 5(2)^{1}$

maximum decomposition rate of soil organic matter with intermediate turnover, the fraction of the pool that turns over each year $\left(0.46 \mathrm{yr}^{-1}\right)$.

Tree file "tree.100" will contain these values:

Decid*

$\begin{array}{ll}\text { Fcfrac }(3,2)^{*} & \begin{array}{l}\text { C allocation fraction of new production } \\ \text { of fine branches for mature forest (time } \\ (0.10) .\end{array}\end{array}$

type of forest $=1$ if forest is temperaturedeciduous.

Fcfrac $(4,2)^{*} \quad$ C allocation fraction of new production of large wood for mature forest $(0.33)$.

Fcfrac $(5,2)^{*}$

$\mathrm{C}$ allocation fraction of new production of coarse roots for mature forest $(0.08)$.

Tfrten (1)*

Tfrtcn (2)*

Tfrtcw (1)*

Tfrtcw (2)*

Leafdr (1)*

Leafdr (2)*

Leafdr (3)*

Leafdr (4)*

Leafdr (5)*

Leafdr (6)*

Leafdr (7)*

Leafdr (8)*

Leafdr (9)*

Leafdr (10)*

Leafdr (11)*

Leafdr (12)*

Wooddr (1)*

Wooddr (2)*

Wooddr (3)*

Wooddr (4)* maximum fraction of $\mathrm{C}$ allocated to fine roots under maximum water

stress $(0.18)$.

minimum fraction of $\mathrm{C}$ allocated to fine roots with no water stress $(0.05)$.

maximum fraction of $\mathrm{C}$ allocated to fine roots under maximum nutrient stress

(0.18).

minimum fraction of $\mathrm{C}$ allocated to fine roots with no nutrient stress $(0.05)$.

monthly death rate fraction for leaves $\left(0.0 \mathrm{mo}^{-1}\right)$.

monthly death rate fraction for leaves $\left(0.0 \mathrm{mo}^{-1}\right)$.

monthly death rate fraction for leaves $\left(0.0 \mathrm{mo}^{-1}\right)$.

monthly death rate fraction for leaves $\left(0.0 \mathrm{mo}^{-1}\right)$.

monthly death rate fraction for leaves $\left(0.0 \mathrm{mo}^{-1}\right)$.

monthly death rate fraction for leaves $\left(0.0 \mathrm{mo}^{-1}\right)$.

monthly death rate fraction for leaves $\left(0.6 \mathrm{mo}^{-1}\right)$.

monthly death rate fraction for leaves $\left(0.6 \mathrm{mo}^{-1}\right)$.

monthly death rate fraction for leaves $\left(0.6 \mathrm{mo}^{-1}\right)$.

monthly death rate fraction for leaves $\left(0.6 \mathrm{mo}^{-1}\right)$.

monthly death rate fraction for leaves $\left(0.0 \mathrm{mo}^{-1}\right)$.

monthly death rate fraction for leaves $\left(0.0 \mathrm{mo}^{-1}\right)$.

the fraction of leaves which fall at the end of the growing season $\left(0.99 \mathrm{mo}^{-1}\right)$.

maximum monthly death rate fraction for juvenile fine root component $\left(0.80 \mathrm{mo}^{-1}\right)$. for fine branch component $\left(0.003 \mathrm{mo}^{-1}\right)$. maximum monthly death rate fraction for large wood component $\left(0.002 \mathrm{mo}^{-1}\right)$. maximum monthly death rate fraction
Wooddr (5)*

maximum monthly death rate fraction for coarse root component $\left(0.0022 \mathrm{mo}^{-1}\right)$.

Wooddr (6)*

Wrdsrfe*

maximum monthly death rate fraction for mature fine root component $\left(0.18 \mathrm{mo}^{-1}\right)$. fraction of the fine roots that are transferred into the surface litter layer [SRTUCC (1) and METABC (1)] upon fine root death, the remainder of the roots will go to the soil litter layer [SRTUCC (2) and METABC (2)] (0.14).

Wmrtfrac* fraction of fine root production that goes to mature roots $(0.05)$.

Kmrsp (2)* the fraction of net primary production that goes to the maintenance respiration storage pool for trees (1.0).

Fkmrspmx (1)* maximum fraction of live leaf $\mathrm{C}$ that goes to maintenance respiration for trees $\left(0.205 \mathrm{mo}^{-1}\right)$.

Fkmrspmx (2)*

maximum fraction of juvenile live fine root $\mathrm{C}$ that goes to maintenance respiration for trees $\left(0.28 \mathrm{mo}^{-1}\right)$.

Fkmrspmx (3)*

maximum fraction of live fine branch $\mathrm{C}$ that goes to maintenance respiration for trees $\left(0.0045 \mathrm{mo}^{-1}\right)$.

Fkmrspmx (4)* maximum fraction of live large wood C that goes to maintenance respiration for trees $\left(0.0045 \mathrm{mo}^{-1}\right)$.

Fkmrspmx (5)*

maximum fraction of live coarse root $\mathrm{C}$ that goes to maintenance respiration for trees $\left(0.007 \mathrm{mo}^{-1}\right)$.

Fkmrspmx (6)* maximum fraction of mature live fine root $\mathrm{C}$ that goes to maintenance respiration for trees $\left(0.26 \mathrm{mo}^{-1}\right)$.

Fgresp (1)* maximum fraction of live leaf $\mathrm{C}$ that goes to growth respiration for trees (0.233).

Fgresp (2)*

Fgresp (3)*

Fgresp (4)*

Fgresp (5)*

Fgresp (6)*

Tmix*

Tmplff*

maximum fraction of juvenile live fine root $\mathrm{C}$ that goes to respiration for trees (0.233).

maximum fraction of live fine branch $\mathrm{C}$ that goes to growth respiration for trees (0.233).

maximum fraction of live large wood $\mathrm{C}$ that goes to growth respiration for trees (0.233).

maximum fraction of live coarse root $\mathrm{C}$ that goes to growth respiration for trees (0.233).

maximum fraction of mature live fine root $\mathrm{C}$ that goes to growth respiration for trees $(0.233)$.

maximum rate of mixing of surface SOM2C and soil SOM2C for forest system $\left(0.22 \mathrm{mo}^{-1}\right)$.

temperature at which leaf drop will occur for a deciduous tree type, degrees $\mathrm{C}\left(70.0^{\circ} \mathrm{C}\right)$. 
Tmplfs*

temperature at which leaf out will occur for a deciduous tree type, degrees $\mathrm{C}\left(10.0^{\circ} \mathrm{C}\right)$.

Wdgrwm* number of months after growth starts that the woody growth stops and the carbon and nutrients that would have been allocated for woody component fine branch, large wood, and coarse root tree growth is instead stored in the carbohydrate (CARBOSTG $(2,1)$ and CARBOSTG $(2,2))$ and nutrient (FORSTG (3)) storage pools (4 mo).

Tmxturn* maximum turnover rate per month of juvenile fine roots to mature fine roots through aging $\left(0.12 \mathrm{mo}^{-1}\right)$.

Site and control parameters

Sitlat*
Sitlng*
Sand*
Silt*
Clay*
Bulkd*

latitude of model site $\left(36.0^{\circ}\right)$. longitude of model site $\left(-82.3^{\circ}\right)$. fraction of sand in soil $\left(0.28^{\circ}\right)$. fraction of silt in soil $\left(0.60^{\circ}\right)$. fraction of clay in soil $(0.12)$. bulk density of soil used to compute soil loss by erosion, wilting point, and field capacity $(1.27 \mathrm{~kg} / \mathrm{liter})$.

Nlayer number of soil layers in water model; used only to calculate the amount of water available for survival of the plant (9).

Nlaypg number of soil layers in the top level of the water model; determines $\operatorname{avh}_{2} \mathrm{O}(1)$, used for growth and root death (4).

External nutrient input parameters

Epnfa (1)*

intercept value for determining the effect of annual precipitation on atmospheric $\mathrm{N}$ fixation (wet and dry deposition) ( $\left.0.05 \mathrm{~g} \mathrm{~N} \mathrm{~m}^{-2} \mathrm{yr}^{-1}\right)$.

Epnfa $(2)^{*} \quad$ slope value for determining the effect of annual precipitation on atmospheric $\mathrm{N}$ fixation (wet and dry deposition $\left(0.007 \mathrm{~g} \mathrm{~N} \mathrm{~m}^{-2} \mathrm{yr}^{-1} \mathrm{~cm}^{-1}\right)$.

Epnfs (1)* minimum AET value used for determining the effect of annual evapotranspiration on nonsymbiotic soil $\mathrm{N}$ fixation $(30 \mathrm{~cm})$.

Epnfs (2)* intercept value for determining the effect of annual evapotranspiration (AET) nonsymbiotic soil $\mathrm{N}$ fixation (0.009 $\mathrm{g} \mathrm{N} \mathrm{m}^{-2} \mathrm{yr}^{-1} \mathrm{~cm}^{-1}$ AET).

[41] Acknowledgments. Funding for the Enriched Background Isotope Study project was provided by the U.S. Department of Energy, Office of Science, Office of Biological and Environmental Research under contract DE-AC02-05CH11231, as a part of the Terrestrial Carbon Processes (TCP) Program.

\section{References}

Aerts, R., H. de Caluwe, and B. Beltman (2003), Plant community mediated vs. nutritional controls on litter decomposition rates in grasslands, Ecology, 84(12), 3198-3208, doi:10.1890/02-0712.

Cisneros-Dozal, L. M., S. E. Trumbore, and P. J. Hanson (2007), Effect of moisture on leaf litter decomposition and its contribution to soil respiration in a temperate forest, J. Geophys. Res., 112, G01013, doi:10.1029/ 2006JG000197.

Coleman, K., and D. S. Jenkinson (1996), RothC-26.3-A model for the turnover of carbon in soil, in Evaluation of Soil Organic Matter Models Using Existing Long-Term Datasets, vol. 38, edited by S. Powlson, P. Smith, and J. U. Smith, pp. 237-246, Springer, Berlin.

DelGrosso, S. J., W. J. Parton, and A. R. Mosier (2001a), Simulated interaction of carbon dynamics and nitrogen trace gas fluxes using the DAYCENT model, in Modeling Carbon and Nitrogen Dynamics for Soil Management, edited by M. Schaffer, L. Ma, and S. Hansen, CRC Press, Boca Raton, Fla.

DelGrosso, S. J., W. J. Parton, and A. R. Mosier (2001b), Simulated effects of land use, soil texture, and precipitation on $\mathrm{N}$ gas emissions using DAYCENT, in Nitrogen in the Environment: Sources, Problems, and Management, edited by R. F. Follett and J. L. Hatfield, Elsevier, Amsterdam, Netherlands, doi:10.1016/B978-044450486-9/50018-2.

DelGrosso, S. J., A. R. Mosier, and W. J. Parton (2005), DAYCENT model analysis of past and contemporary soil $\mathrm{N}_{2} \mathrm{O}$ and net greenhouse gas flux for major crops in the USA, Soil Tillage Res., 83, 9-24, doi:10.1016/j. still.2005.02.007.

DeLucia, E. H., J. E. Drake, R. B. Thomas, and M. Gonzalez-Meier (2007), Forest carbon use efficiency: Is respiration a constant fraction of gross primary production?, Global Change Biol., 13, 1157-1167, doi:10.1111/j.1365-2486.2007.01365.x.

Dornbush, M. E., T. M. Isenhart, and J. W. Raich (2002), Quantifying fineroot decomposition: An alternative to buried litterbags, Ecology, 83, 2985-2990, doi:10.1890/0012-9658(2002)083[2985:QFRDAA]2.0. $\mathrm{CO} ; 2$.

Eitzinger, J., W. J. Parton, and M. Hartman (2000), Improvement and validation of a daily soil temperature submodel for freezing/thawing periods, Soil Sci., 165(7), 525-534, doi:10.1097/00010694-200007000-00001.

Falloon, P. D., P. Smith, and K. Coleman (1998), Estimating the size of the inert organic matter pool for use in the Rothamsted carbon model, Soil Biol. Biochem., 28, 1367-1372.

Follett, R. F., E. A. Paul, and E. G. Pruessner (2007), Soil carbon dynamics during a long-term incubation study involving ${ }^{13} \mathrm{C}$ and ${ }^{14} \mathrm{C}$ measurements, Soil Biol. Biochem., 172, 189-208.

Fröberg, M., P. M. Jardine, and P. J. Hanson (2007), Low dissolved organic carbon input from fresh litter to deep mineral soils, Soil Sci. Soc. Am. J., 71, 347-354, doi:10.2136/sssaj2006.0188.

Fröberg, M., P. J. Hanson, S. E. Trumbore, C. W. Swanston, and D. E. Todd (2009), Flux of carbon from ${ }^{14} \mathrm{C}$-enriched leaf litter throughout a forest soil mesocosm, Geoderma, 149, 181-188, doi:10.1016/j.geoderma.2008.11.029.

Frolking, S. E., A. R. Mosier, and D. S. Ojima (1998), Comparison of $\mathrm{N}_{2} \mathrm{O}$ emissions from soils at three temperate agricultural sites: Simulations of year-round measurements by four models, Nutr. Cycl. Agroecosyst., 52, 77-105, doi:10.1023/A:1009780109748.

Hanson, P. J., D. E. Todd, and D. C. West (2003a), Tree and sapling growth and mortality, in North American Temperate Deciduous Forest Responses to Changing Precipitation Regimes, edited by P. J. Hanson and S. D. Wullschleger, Springer, New York.

Hanson, P. J., E. G. O’Neill, and M. L. S. Chambers (2003b), Soil respiration and litter decomposition, in North American Temperate Deciduous Forest Responses to Changing Precipitation Regimes, edited by P. J. Hanson and S. D. Wullschleger, Springer, New York.

Hanson, P. J., C. W. Swanston, and C. T. Gartgen Jr. (2005), Reconciling change in Oi-horizon carbon-14 with mass loss for an oak forest, Soil Sci. Soc. Am. J., 69, 1492-1502, doi:10.2136/sssaj2004.0300.

Hobbie, S. E. (1996), Temperature and plant species control over litter decomposition in Alaskan tundra, Ecol. Monogr., 66, 503-522, doi: $10.2307 / 2963492$

Jenkinson, D. S. (1971), Studies on the decomposition of ${ }^{14}$ C-labeled organic matter in soil, Soil Sci., 111, 64-70, doi:10.1097/00010694197101000-00008.

Joslin, J. D., J. B. Gaudinski, and M. S. Torn (2006), Fine root turnover patterns and their relationship to root diameter and soil depth in a ${ }^{14} \mathrm{C}$ labeled hardwood forest, New Phytol., 172, 523-535, doi:10.1111/ j.1469-8137.2006.01847.x. 
Kelly, R. H., W. J. Parton, and C. J. Crocker (1997), Simulating trends in soil organic carbon in long-term experiments using the Century model, Geoderma, 81, 75-90, doi:10.1016/S0016-7061(97)00082-7.

Kelly, R. H., W. J. Parton, and M. D. Hartman (2000), Intra- and interannual variability of ecosystem processes in shortgrass steppe, J. Geophys. Res., 105, 20,093-20,100, doi:10.1029/2000JD900259.

Li, C., S. Frolking, and R. Harriss (1994), Modeling carbon biogeochemistry in agricultural soils, Global Biogeochem. Cycles, 8(3), 237-254, doi:10.1029/94GB00767.

Litton, C. M., M. G. Ryan, and J. W. Raich (2007), Carbon allocation in forest ecosystems, Global Change Biol., 13, 2089-2109, doi:10.1111/ j.1365-2486.2007.01420.x.

Lousier, J. D., and D. Parkinson (1976), Litter decomposition in a cool temperature deciduous forest, Can. J. Bot., 54, 419-436.

Luo, Y., et al. (2008), Modeled interactive effects of precipitation, temperature, and $\mathrm{CO}_{2}$ on ecosystem carbon and water dynamics in different climatic zones, Global Change Biol., 14, 1986-1999, doi:10.1111/j.1365-2486.2008.01629.x.

McClaran, M. P., and G. R. McPherson (1995), Can soil organic carbon isotopes be used to describe grass-tree dynamics at a savanna-grassland ecotone and within the savanna?, J. Veg. Sci., 6(6), 857-862, doi: $10.2307 / 3236400$

McClaugherty, C. A., J. Pastor, and J. D. Aber (1985), Forest litter decomposition in relation to soil nitrogen dynamics and litter quality, Ecology, 66(1), 266-275, doi:10.2307/1941327.

Meentemeyer, V. (1978), Macroclimate the lignin control of litter decomposition rates, Ecology, 59(3), 465-472, doi:10.2307/1936576.

Melillo, J. M., J. D. Aber, and J. F. Muratore (1982), Nitrogen and lignin control of hardwood leaf litter decomposition dynamics, Ecology, 63(3), 621-626, doi: $10.2307 / 1936780$.

Osher, L. J., P. A. Matson, and R. Amundson (2003), Effect of land use change on soil carbon in Hawaii, Biogeochemistry, 65(2), 213-232, doi:10.1023/A:1026048612540.

Parton, W. J., J. S. Singh, and D. C. Coleman (1978), A model of production and turnover of roots in shortgrass prairie, J. Appl. Ecol., 47, 515-542, doi: $10.2307 / 2402608$

Parton, W. J., D. S. Schimel, and C. V. Cole (1987), Analysis of factors controlling SOM levels in Great Plains grasslands, Soil Sci. Soc. Am. J., 51, 1173-1179, doi:10.2136/sssaj1987.03615995005100050015x.

Parton, W. J., M. Hartman, and D. S. Ojima (1998), DAYCENT and its land surface submodel: Description and testing, Global Planet. Change, 19, 35-48, doi:10.1016/S0921-8181(98)00040-X.

Parton, W. J., E. A. Holland, and S. J. Del Grosso (2001), Generalized model for $\mathrm{NO}_{\mathrm{x}}$ and $\mathrm{N}_{2} \mathrm{O}$ emissions from soils, J. Geophys. Res., 106, 17,403-17,420, doi:10.1029/2001JD900101.

Parton, W. J., W. L. Silver, and I. C. Burke (2007a), Global-scale similarities in nitrogen release patterns during long-term decomposition, Science, 315, 361-364, doi:10.1126/science.1134853.

Parton, W. J., J. A. Morgan, and G. Wang (2007b), Projected ecosystem impact of the prairie heating and $\mathrm{CO}_{2}$ enrichment experiment, New Phytol., 174, 823-834, doi:10.1111/j.1469-8137.2007.02052.x.

Paul, E. A., R. F. Follett, and S. W. Leavitt (1997), Radiocarbon dating for determination of SOM pool sizes and dynamics, Soil Sci. Soc. Am. J., 61, 1058-1067, doi:10.2136/sssaj1997.03615995006100040011x.

Pepper, D. A., S. J. DelGrosso, and R. E. McMurtrie (2005), Simulated carbon sink response of shortgrass steppe, tallgrass prairie, and forest ecosystems to rising $\left(\mathrm{CO}_{2}\right)$ temperature and nitrogen input, Global Biogeochem. Cycles, 19, GB1004, doi:10.1029/2004GB002226.
Petersen, B. M., J. Berntsen, and S. Hansen (2005a), CN-SIM-A model for the turnover of SOM. I: Long term carbon development, Soil Biol. Biochem., 37, 359-374, doi:10.1016/j.soilbio.2004.08.006.

Petersen, B. M., L. S. Jensen, J. Berntsen, and S. Hansen (2005b), CN-SIM-A model for the turnover of SOM. II: Short term carbon and nitrogen development, Soil Biol. Biochem., 37, 375-393, doi:10.1016/j. soilbio.2004.08.007.

Riley, W. J., J. B. Gaudinski, M. S. Torn, J. D. Joslin, and P. J. Hanson (2009), Fine-root mortality rates in a temperate forest: Estimates using radiocarbon data and numerical modeling, New Phytol., 184, 387-398, doi:10.1111/j.1469-8137.2009.02980.x

Running, S. W., and J. C. Coughlan (1988), A general model of forest ecosystem processes for regional applications, I. Hydrologic balance, canopy gas exchange and primary production processes, Ecol. Modell., 42, 125-154, doi:10.1016/0304-3800(88)90112-3.

Ryan, M. G., S. T. Gower, and R. M. Hubbard (1995), Woody tissue maintenance respiration of four conifers in contrasting climates, Oecologia, 101, 133-140, doi:10.1007/BF00317276.

Ryan, M. G., R. M. Hubbard, S. Pongracic, R. J. Raison, and R. E. McMurtrie (1996), Foliage, fine-root, woody-tissue and stand respiration in Pinus radiata in relation to nitrogen status, Tree Physiol., 16, 333-343.

Shanks, R. E., and J. S. Olson (1961), First-year breakdown of leaf litter in southern Appalachian forests, Science, 134, 194-195, doi:10.1126/science.134.3473.194.

Steuter, A. A., B. Jasch, and J. Ihnen (1990), Woodland/grassland boundary changes in the middle Niobrara Valley of Nebraska identified by $\delta^{13} \mathrm{c}$ values of SOM, Am. Midl. Nat., 124(2), 301-308, doi:10.2307/2426179.

Swanston, C. W., M. S. Torn, and P. J. Hanson (2005), Initial characterization of processes of soil carbon stabilization using forest stand-level radiocarbon enrichment, Geoderma, 128, 52-62, doi:10.1016/j.geoderma.2004.12.015.

Trofymow, J. A., T. R. Moore, and B. D. Titus (2002), Rates of litter decomposition over 6 years in Canadian forests: Influence of litter quality and climate, Can. J. For. Res., 32, 789-804, doi:10.1139/x01-117.

Trumbore, S., J. B. Gaudinski, and P. J. Hanson (2002), A whole-ecosystem carbon-14 label in a temperate forest, Eos Trans. $A G U, 83(265)$, 267-268.

Wang, Y., R. Amundson, and S. Trumbore (1996), Radiocarbon dating of SOM, Quat. Res., 45(3), 282-288, doi:10.1006/qres.1996.0029.

Waring, R. H., J. J. Landsberg, and M. Williams (1998), Net primary production of forests: A constant fraction of gross primary production?, Tree Physiol., 18, 129-134.

Wieder, R. K., and G. E. Lang (1982), A critique of the analytical methods used in examining decomposition data obtained from litter bags, Ecology, 63(6), 1636-1642, doi:10.2307/1940104.

P. J. Hanson, Oak Ridge National Laboratory, Oak Ridge, TN 37831, USA.

R. Kelly and W. J. Parton, Natural Resource Ecology Laboratory, Colorado State University, Fort Collins, CO 80523-1499, USA. (billp@ nrel.colostate.edu)

W. Riley and M. Torn, Lawrence Berkeley National Laboratory, Berkeley, CA 94720, USA

C. Swanston, Northern Research Station, U.S. Forest Service, Houghton, MI 49931, USA.

S. E. Trumbore, School of Physical Sciences, University of California, Irvine, CA 92697, USA. 